\title{
Development of a music perception test for adult hearing-aid users
}

\author{
Marinda Uys \\ Department of Communication Pathology, University of Pretoria
}

Catherine van Dijk
Department of Communication Pathology, University of Pretoria; Ear Institute, Queenswood, Pretoria

Correspondence to: M Uys (marinda.uys@gmail.com)

\begin{abstract}
The purpose of this research was twofold: firstly, to develop a music perception test (MPT) for hearing-aid users, and secondly, to evaluate the influence of non-linear frequency compression (NFC) on music perception with the use of the self-compiled test. This article focuses on the description of the development and validation of the MPT. To date, the main direction in frequency-lowering hearing-aid studies has been in relation to speech perception abilities. As hearing-aid technology has improved, interest has grown in musical perception as a dimension that could improve hearing-aid users' quality of life. The MPT was designed to evaluate different aspects of rhythm, timbre, pitch and melody. The development of the MPT could be described as design-based. Phase 1 of the study included test development and recording, while phase 2 entailed presentation of stimuli to normal hearing listeners $(n=15)$ and hearing-aid users $(n=4)$. Based on the findings of phase 2, item analysis was performed to eliminate or change stimuli that resulted in high error rates. During phase 3 the adapted version of the test was performed on a smaller group of normal hearing listeners $(n=4)$ and 20 hearing-aid users. Results proved that adults with normal hearing as well as adults using hearing aids were able to complete all the sub-tests of the MPT, although hearing-aid users scored lower on the various sub-tests than normal hearing listeners. For the rhythm section of the MPT normal hearing listeners scored on average $93.8 \%$ versus $75.5 \%$ of hearing-aid users; for the timbre section the scores were $83 \%$ versus $62.3 \%$ respectively. Normal hearing listeners obtained an average score of $86.3 \%$ for the pitch section and $88.2 \%$ for the melody section, compared with the $70.8 \%$ and $61.9 \%$ respectively obtained by hearing-aid users. This implies that the MPT can be used successfully for assessment of music perception in hearing-aid users within the South African context and may therefore result in more effective hearing-aid fittings taking place. The test can be used as a counselling tool to assist audiologists and patients in understanding the problems they experience regarding music perception, and might be used for future musical training in areas where participants experience problems in customising individual fittings.
\end{abstract}

Keywords: hearing loss, music perception, non-linear frequency compression, hearing aids, sensory neural hearing loss, cochlear dead regions

High-frequency hearing loss is by far the most common audiometric configuration found in individuals fitted with hearing instruments (Nyffeler, 2008), and high-frequency amplification plays an important role in speech understanding (Glista \& McDermott, 2008). However, speech comprehension is not the only ability adversely affected by highfrequency hearing loss. Music and lyrics can be difficult to detect or identify as well (Glista \& McDermott, 2008), which is problematic as music enhances one's quality of life. While enjoyment is certainly one of its main purposes, music also serves as a medium that models social structures, facilitates the acquisition of social competence by young people, and provides human interaction (Cross, 2006).

Some people may not know that they have cochlear dead regions, and perceive high-frequency amplification as distorted or noise-like in quality (Munro, 2007; Vestergaard, 2003). Frequency-discrimination measurements also suggest that frequency tones falling in a dead region do not evoke a clear pitch or may have an abnormal timbre (McDermott \& Dean, 2000). Individuals with a cochlear dead region may therefore have different frequency-gain requirements from those without a dead region. Diagnosis of the presence and extent of a dead region may have important clinical implications for candidature for and benefit from amplification (Cairns, Frith, Munro \& Moore, 2007), counselling and hearing instrument selection (Munro, 2007).

Many researchers have suggested the possibility of frequency lowering as a means of making speech sounds audible for patients with dead regions (Moore, 2009; Bagatto, Scollie, Glista, Parsa \& Seewald, 2008; Moore \& Alcantara, 2001). Various research projects have therefore been conducted with frequency-lowering hearing instruments that focused on improved speech perception (Kuk, Keenan, Korhonen \& Lau, 2009; Stuermann, 2009; Bagatto et al., 2008; Robinson, Baer \& Moore, 2007; Simpson, Hersbach \& McDermott, 2006; Simpson, Hersbach \& McDermott, 2005; Turner \& Hurtig, 1999). An integral part of people's daily lives consists of listening to music and other nonspeech sounds, and currently there are no studies to indicate what the influence of frequency lowering on music perception is (Bagatto et al., 2008).

The majority of people wearing hearing instruments complain of the reduced sound quality of music heard through them (Chasin, 2003). This may be due to the fact that most hearing instruments are designed with the focus on hearing speech and not music, which is problematic as there are several main differences between music and speech. ${ }^{1}$ Furthermore, more and more people with hearing loss are expressing an equal need for their hearing instruments to be fitted optimally for listening to music (Chasin, 2004), and concern about the fidelity of music processed by hearing instruments has emerged. The escalating interest in musical perception accuracy and enjoyment is also reflected in publications of a variety of investigations utilising different experiments to assess performance on musical tasks (Cooper, Tobey \& Loizou, 2008; Fujita \& Ito, 1999; Gfeller, Olszewski, Rychener, Sena, Knutson, Witt \& Macpherson, 2005; Gfeller, Turner, Mehr, Woodworth, Fearn, Knutson, Witt \& Stordahl, 2002; Gfeller, Woodworth, Robin, Witt \& Knutson, 1997; Gfeller \& Lansing, 1991; Looi, McDermott, McKay \& Hickson, 2008; Nimmons et al., 2008; Spitzer, Mancuso \& Cheng, 2008).

Almost all of the abovementioned research focuses on music perception in persons with cochlear implants. This began by adapting the Primary Measures of Music Audition test and developing the Musical Excerpt

1 The differences between music and speech are described in detail by Chasin (2010), as well as Chasin and Russo (2004)

2 Reasons why these tests were not used in the current study include: most of them were developed fo assessment of music perception in cochlear implantees, only addressed limited areas of musical perception, stimuli included melodies familiar to the American, Australian, Asian or European cultures, they wer lengthy tests that require trained musical personnel to code the responses, or they were computerised which can be problematic for everyday use in the South African context because of limited resources and facilities. 
Recognition test (Gfeller et al., 2005; Gfeller et al., 1997; Gfeller \& Lansing, 1991). Many other groups have also assembled in-house tests to evaluate cochlear implant strategies and designs developed by their laboratories (Kong, Stickney \& Zeng, 2005). The instruments used in these studies were designed to address specific research questions regarding perception of different structural features of music. The methods used were often similar, but they were not intended to be standardised tests and it is therefore not possible to directly compare results across laboratories (Nimmons et al., 2008). Furthermore, most of these tests were developed to examine the music perception skills of persons with cochlear implants and were therefore not applicable to the evaluation of persons using hearing aids. Not only is the technology for music as input to hearing aids still in its infancy, but the research and clinical knowledge of what music lovers need to hear is also still in its early stages of understanding; more research is required in this area (Chasin \& Russo, 2004).

Music is highly complex (Leal et al., 2003) and therefore music perception by persons wearing hearing aids is difficult to assess. A basic observation of music psychology is that listening to music may give rise to a large variety of experiences that are based on highly interrelated emotional and cognitive processes in the brain (Kreutz, Schubert \& Mitchell, 2008; Iakovides, Iliadou, Bizeli, Kaprinis, Fountoulakis \& Kaprinis, 2004). For example, one individual's deepest appreciation may be based on the structural features of a musical work, whereas for another the emotional content of a piece of music may elicit strong experiences. The possibility arises that music processing depends on cognitive styles that vary between individuals, as well as numerous participative factors that influence enjoyment, including personal preferences for musical genres and the situational context, such as the listening environment and the listener's mood (Kreutz et al., 2008; Nimmons et al., 2008). The effect of temporal context in music - what was played before and what is about to be played - influences a listener's experience. An identical physical stimulus may be perceived differently, depending on the context; therefore, music perception is a dynamic, time-dependent process. These participative factors mentioned above may all greatly affect music perception and thereby render it difficult to measure.

Furthermore, no standard test of music perception exists (Wessel, Fitz, Battenberg, Schmeder \& Edwards, 2007) and the few music perception tests that are available on the market are advanced and designed to examine the skills of individuals with formal musical training (Don, Schellenberg \& Rourke, 1999). Previous studies (Gfeller et al., 2005; Gfeller et al., 2002; Gfeller et al., 1997; Gfeller \& Lansing, 1991) confirmed the difficulty of assessing musical perception and highlighted the need for a clinically relevant measure of musical recognition and performance (Spitzer et al., 2008). Therefore, in order to determine the music perception of hearing-aid users, the MPT for the assessment of music perception in adult hearing-aid users was compiled.

\section{Method}

\section{Aims}

The main aim of the study was to determine the test performance of adults presenting with normal hearing and those presenting with a moderate to severe hearing loss, wearing hearing instruments on the self-compiled MPT.

This aim was accomplished by means of the following secondary aims in order to ensure that the MPT is suitable for assessment of music perception in hearing-aid users:

- to evaluate the performance of adults presenting with normal hearing on the pilot (phase 2) and revised (phase 3) versions of the MPT

- to evaluate the performance of adults presenting with a moderate to severe hearing loss who are wearing hearing aids on the pilot and revised versions of the MPT

- to compare the results obtained from adults with normal hearing with those of adults wearing hearing aids.

\section{Study design}

To develop a measurement tool for music perception of hearing aid users, three study phases were planned. In phase $\mathbf{1}$, test developing and recording of the MPT took place and can be described as design-based. Although this paradigm is mostly applied to educational contexts (Barab \& Squire, 2004), it provides a suitable framework for this phase, which involved the design of a test. The principles of this approach were applied by using theoretical knowledge and literature to compile test material potentially suitable for the assessment of music perception in South African adults with hearing loss. Phases 2 and 3 can be described as quantitative with a quasi-experimental design. During phase 2 , trials with normal hearing participants and a small group of hearing-aid users were performed, followed by item analysis to eliminate or change items that had high error rates. In phase 3 , the adapted version of the MPT was administered to a smaller group of participants with normal hearing and 20 hearing-aid users for final analysis of test items. This was done in order to improve the validity and reliability of the test.

\section{Ethical aspects}

Ethical clearance for this study was obtained from the institutions involved. As the underlying foundation of ethical research is to preserve and protect the human dignity and rights of all the participants participating in a research study (Jenkins, Price \& Starker, 2003), the ethical principles of autonomy, beneficence and justice were adhered to (Leedy \& Ormrod, 2005).

\section{Participants}

The researcher made use of a purposive convenient sampling method where participants were chosen on the basis of accessibility and because they articulated with the aims of the study (Babbie, 2005). The 15 normal hearing adults who participated in phase 2 and the 4 normal hearing adults who participated in phase 3 met the following criteria:

- $\quad$ bilateral hearing thresholds for octave frequencies between $125 \mathrm{~Hz}$ and $8000 \mathrm{~Hz}$ at $20 \mathrm{~dB}$ HL or better (Van Deun et al., 2009)

- English language proficiency and literacy

- South African citizens

- no minimal musical background or experience level was required. Participants were however asked to indicate if they had any formal musical training.

The mean age of the normal hearing persons who participated in phases 2 and 3 was 39.5 years (range 22 to 64 years). Only 4 of the adults included in phase 2 had formal musical training, while 1 adult included in phase 3 indicated this. The length of musical training received by these adults ranged between 2 and 7 years (phase 2: 4 years, 2 years, 3 years and 2 years; phase 3: 7 years).

It was important to verify the music test initially with a group of normal hearing listeners to ensure that the test was appropriate for administration with participants with hearing loss (Looi et al., 2008). To demonstrate the feasibility of this test for clinical application, persons with hearing instruments were recruited for phase 2 and phase 3 . The hearing-aid users who participated in phase $2(n=4)$ and phase $3(n=20)$ met the following criteria:

- $\quad$ bilateral, moderate to severe sensory neural hearing loss, with a pure tone average of $41-90 \mathrm{~dB}$ at the frequencies $500 \mathrm{~Hz}, 1000 \mathrm{~Hz}$ and $2000 \mathrm{~Hz}$ (Plante \& Beeson, 1999)

- current digital hearing instrument use. Hearing instruments were verified electro-acoustically to ensure that they were working properly and real-ear measurements were done to ensure that hearing instruments were optimised to reflect the current best practice (Auriemmo et al., 2009)

- English language proficiency and literacy

- South African citizens

- no minimal musical background or experience level was required. Participants were, however, asked to indicate if they had any formal musical training.

Tables I and II provide the biographical information on hearing-aid users in phases 2 and 3 , respectively. 
Table I. Biographical information of participants with hearing aids included in phase 2

\begin{tabular}{|c|c|c|c|c|}
\hline Biographical information & P1 & P2 & P3 & $\mathbf{P 4}$ \\
\hline Age & 64 years & 64 years & 43 years & 60 years \\
\hline Cause of hearing loss & Noise-induced & Noise-induced & Unknown & Unknown \\
\hline Shape of hearing loss & $\begin{array}{l}\text { R: Sloping } \\
\text { L: Flat }\end{array}$ & $\begin{array}{l}\text { R: Sloping } \\
\text { L: Sloping }\end{array}$ & $\begin{array}{l}\text { R: Flat } \\
\text { L: Flat }\end{array}$ & $\begin{array}{l}\text { R: Sloping } \\
\text { L: Sloping }\end{array}$ \\
\hline Pure tone average (PTA) & $\begin{array}{l}\text { R: } 75 \mathrm{~dB} \\
\text { L: } 63 \mathrm{~dB}\end{array}$ & $\begin{array}{l}\text { R: } 60 \mathrm{~dB} \\
\text { L: } 60 \mathrm{~dB}\end{array}$ & $\begin{array}{l}\text { R: } 63 \mathrm{~dB} \\
\text { L: } 62 \mathrm{~dB}\end{array}$ & $\begin{array}{l}\text { R: } 60 \mathrm{~dB} \\
\text { L: } 60 \mathrm{~dB}\end{array}$ \\
\hline Oto-acoustic emissions & $\begin{array}{l}\text { R: Absent } \\
\text { L: Absent }\end{array}$ & $\begin{array}{l}\text { R: Absent } \\
\text { L: Absent }\end{array}$ & $\begin{array}{l}\text { R: Absent } \\
\text { L: Absent }\end{array}$ & $\begin{array}{l}\text { R: Absent } \\
\text { L: Absent }\end{array}$ \\
\hline Current hearing aids & $\begin{array}{l}\text { R: Extra } 311 \\
\text { L: Extra } 211\end{array}$ & $\begin{array}{l}\text { R: Extra } 411 \\
\text { L: Extra } 411\end{array}$ & $\begin{array}{l}\text { R: Una M AZ } \\
\text { L: Una M AZ }\end{array}$ & $\begin{array}{l}\text { R: Extra } 33 \\
\text { L: Extra } 33\end{array}$ \\
\hline Signal processing scheme & dSC & dSC & dWDRC & dSC \\
\hline Time wearing hearing aids & 4 years & 5 years & 10 years & 9 years \\
\hline Musical training received & None & None & 3 years & 1 year \\
\hline
\end{tabular}

The average age for hearing-aid users in phase 2 was 57.8 years (range 43 - 64 years) and for participants in phase 357.5 years (range 34 64 years). All participants had a post-lingual onset of hearing loss and were evaluated with their current hearing aids on an omnidirectional microphone setting with the noise-cancellers inactive.

\section{Procedures}

The following sections provide detail about the test development and procedures followed.

\section{Test development: phase 1}

As several subjective factors ${ }^{3}$ can affect music perception, the MPT was designed to focus on the objective characteristics of music, which can be described in terms of physical parameters of the acoustic signal (Nimmons et al., 2008). Therefore, structural features of music (rhythm, timbre, pitch and melody) were included. The researcher, in consultation with sound engineers and musicians, generated a list of musical stimuli for the different categories of the test. Specific components were selected based on existing literature (Gfeller et al., 2005; Gfeller et al., 2002; Gfeller et al., 1997; Gfeller \& Lansing, 1991) as well as consensus between the audiologist, sound engineers and musicians. In order to optimise the reliability and validity of the MPT, the following aspects were implemented during development of the test:

- A thorough study of previous music perception tests and experiments described in the literature was conducted.

- The MPT recordings were of a high quality, as the test was recorded in a professional music studio by professional musicians and sound engineers.

- Wherever possible, the stimuli have been recorded to give a range from gross differences to very subtle changes. This is important, as differences in musical stimuli can be so subtle that many normal hearing listeners might be stretched to recognise them (Medel Medical Electronics, 2006).

- Piano tones were used where applicable for stimuli, as piano tones are more commonly available in music. Because of their ecological validity, they are typically used in music perception tasks (Cooper et al., 2008).

- A calibration tone was inserted at the beginning of the recording, and an alerting phrase, 'Are you ready?' was inserted prior to each sub-test. Recognising that music is highly variable in intensity, effort was made to maintain a minimum intensity level within 10 $\mathrm{dB}$ of the calibration tone.

- Recordings were consistent in terms of characteristics. If the duration of a given excerpt is long, it is likely that its timbral and spatial characteristics will vary in time and listeners might find it difficult to 'average' the quality over time and some random errors may occur (Zielinski, Rumsey \& Bech, 2008). Short and consistent stimuli were therefore used in the MPT.

- The issue of familiarity with test stimuli was taken into account. Careful attention must be given to this aspect, as a person's unfamiliarity with test items can be the cause of poor performance. This aspect was addressed in the current study by including melodies that are heard by people in everyday life, and are therefore familiar to persons who have had little or no musical training. Furthermore, participants were given the opportunity to indicate their familiarity with all the melodies included in the test before the actual testing took place. Items with which participants were unfamiliar were not included in the analysis of results.

\section{Categories}

The following categories were included in the MPT:

\section{Section A: Rhythm}

Rhythm identification (sub-test 1). Five groups (1 second 768 milliseconds (ms) in length each) consisting of five pulse tones $(43 \mathrm{~ms}$ in length), spaced $369 \mathrm{~ms}$ apart from one another, except for two pulses which are grouped together with a space of $32 \mathrm{~ms}$ in between, were included. Pulse tones did not differ in frequency. Five different group patterns were used, each differentiated by the position of the short inter-pulse interval. The first group of rhythmical patterns started with close spacing of the tones at the beginning of the group. In the second group, two of the tones were closely spaced at the second pulse tone and the same pattern was followed for the remaining groups. Figure 1 shows the visual presentation of the short interpulse interval at position four.

Participants received a visual representation of the different patterns on the answer sheet. Only ONE of the five groups was randomly played for each test item, and participants were asked to identify which group they heard. To register their response, they marked an $\mathrm{x}$ beneath the visual representation similar to the item heard.

Rhythm discrimination (sub-test 2). This sub-test determined participants' ability to distinguish temporal rhythms and evaluate changes in duration of notes by presenting twelve pairs of short rhythmic pulse patterns separated by 5 seconds of silence. All pulses were presented at the same frequency (B6 (+4 cents)/3 $959.8 \mathrm{~Hz}$ and the patterns were spaced 1.5 seconds apart. The short pulses ranged from $130 \mathrm{~ms}$ to $167 \mathrm{~ms}$, the medium-length pulses from $252 \mathrm{~ms}$ to 457 $\mathrm{ms}$ and the long pulses from $500 \mathrm{~ms}$ to $752 \mathrm{~ms}$. The amplitude for the loud pulses was $-25.4 \mathrm{~dB}$ and for the soft pulses $-30.4 \mathrm{~dB}$. After listening to each pair in turn, participants had to indicate on the answer sheet whether a pair of rhythm patterns was the same or different by marking 'yes' if they were the same or 'no' if they were different.

Rhythm recognition (sub-test 3). Participants were presented with twelve melodies in various key signatures, which were rhythmically 
量

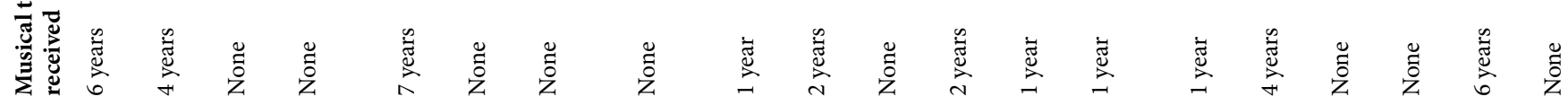

象

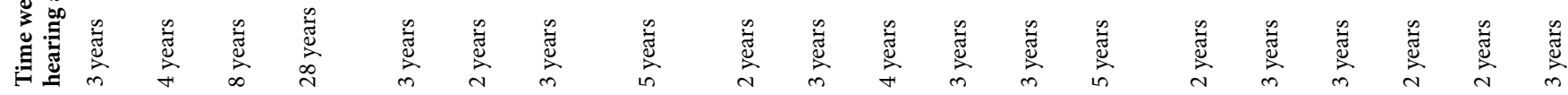

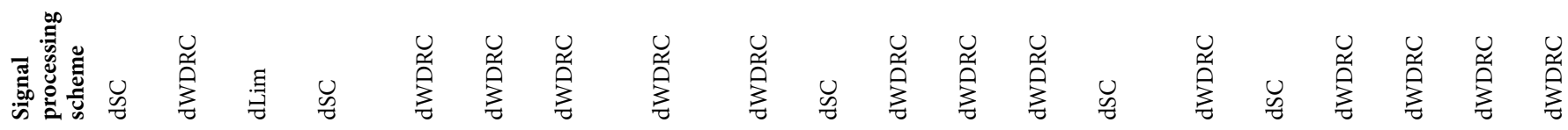

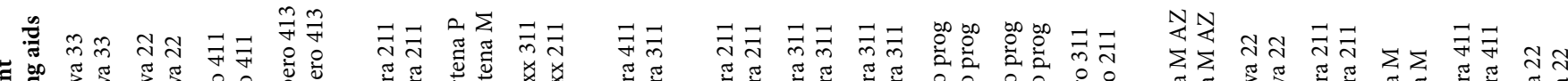

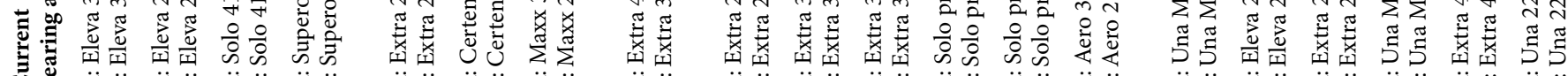

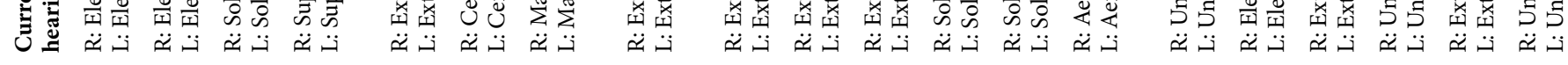

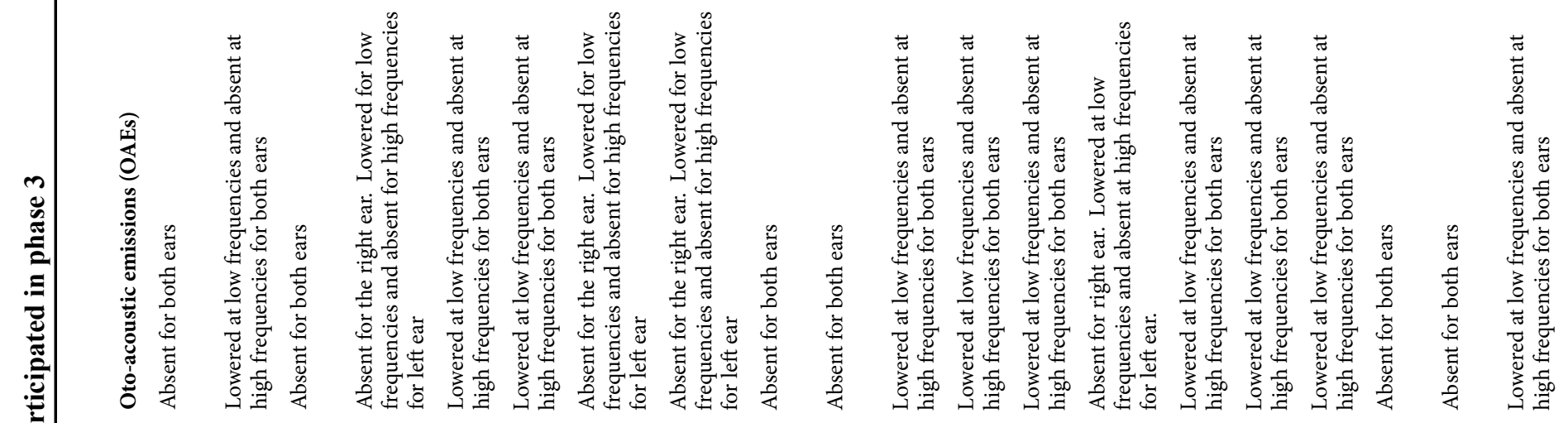

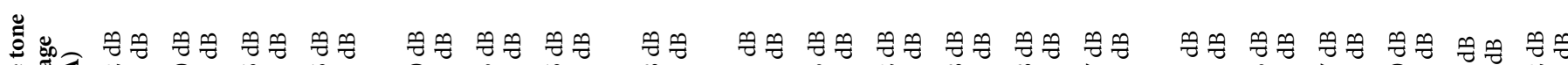

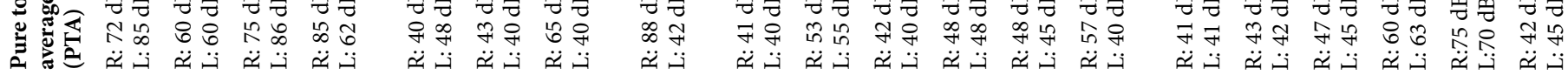

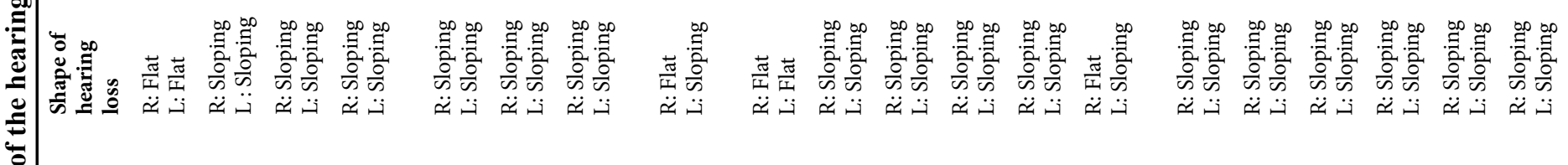

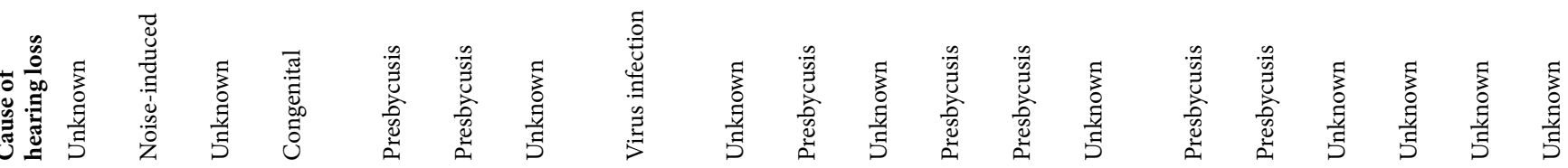

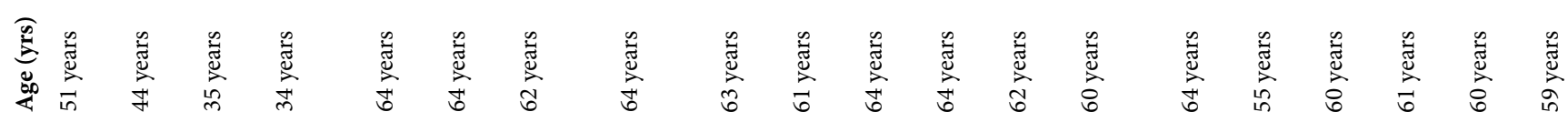
氖 


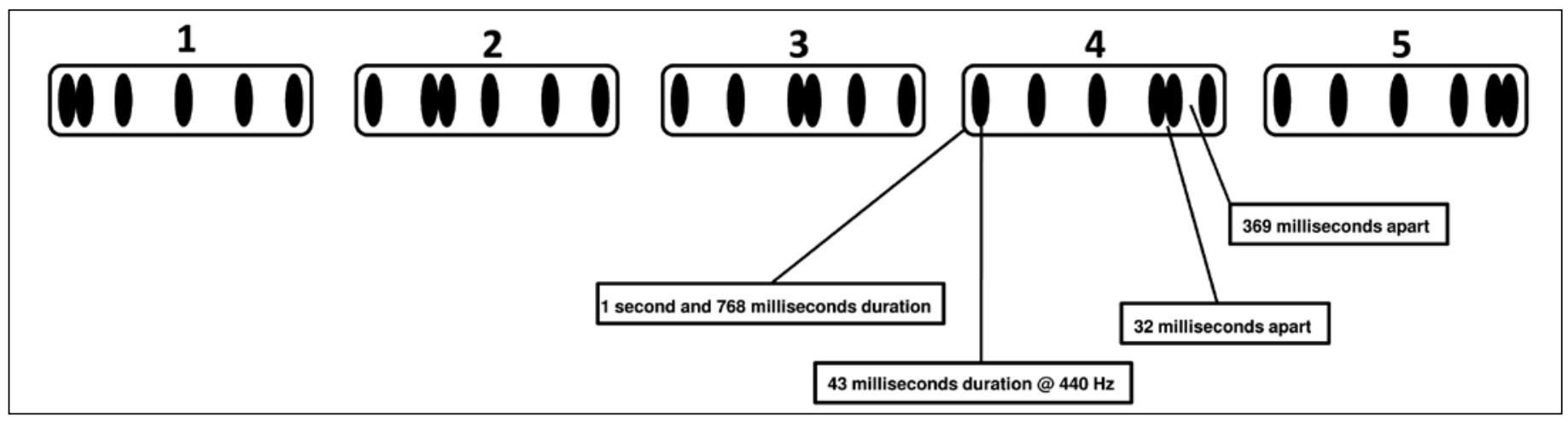

Fig. 1. Visual representation of short interpulse interval at position four.

structured as either a waltz (melodic pattern in triple meter) or a march (melodic pattern in duple meter). Melodies used in this sub-test were specifically composed for this test and had sufficient complexity to guarantee processing as a meaningful structure rather than as a simple sequence of notes. Rhythmical patterns were varied across melodies and the tempos used varied across 100, 120, 150, 180 and 200 beats per minute. The melodies consisted of between 8 and 14 notes and were played on a piano between $\mathrm{D} 4 / 293.7 \mathrm{~Hz}$ and A6/1760 Hz. A second track with rhythmical chords played on an electric piano was added to assist with the indication of the time signature $(4 / 4$ or $3 / 4)$. There was 5 seconds of silence after each melody. Participants had to indicate whether the item they heard was rhythmically structured as a waltz or a march by marking an $\mathrm{x}$ next to the applicable answer on the answer sheet.

Rhythm perception (sub-test 4). Participants were presented with twelve pairs of melodic sequences. In each pair, either the first or the second melody was played rhythmically out of time, i.e. was not musically rhythmical. Melodies were played on a piano with a frequency range of C5/523.3 Hz - G\#6/1661 Hz. Both 4/4 and 3/4 time signatures were used and melodies were in various key signatures. The tempo range for the melodies was between 100 and 150 beats per minute. The melodies in each pair were spaced 1.5 seconds apart, with 5 seconds of silence after each pair. Participants were required to indicate which melodic sequence was played rhythmically in time by selecting 'First', 'Second' or 'Both' on the answer sheet.

\section{Section B: Timbre}

The timbral stimuli used in sub-test 5 (parts 1 and 2) included eight different musical instruments that are commonly known to nonmusicians, represent different fundamental frequency ranges and represent different instrumental families based on the principles of sound production (Gfeller, Witt, Adamek, Mehr, Rogers, Stordahl \& Ringgenberg, 2002).

The trumpet (medium) and trombone (low) represented the brass family and the piccolo flute (high), clarinet (medium), and saxophone (low) represented the woodwind family. The string instruments were represented by the violin (high) and cello (low). Pitched percussion was represented by the piano, which was played in two different frequency ranges (medium and high). Both of these ranges are equally characteristic for the piano (Gfeller et al., 2002). The melodic pattern played by each instrument was composed specifically for use in this test. It consisted of a short melodic piece played by each instrument in $\mathrm{C}$ major at a tempo of 100 beats per minute. The melody consisted of seven quarter-notes, each of equal duration.

To ensure that identification abilities were being assessed, and not musical knowledge, each participant's familiarity with the instruments was verified before testing (Looi et al., 2008). Participants were given a picture of each instrument accompanied by the instrument's name. They were instructed to mark all the instruments they know by sound before the onset of the test. Although instruments were chosen that were considered well known to the general public, musical training and experiences differ considerably across the general population (Gfeller $e t$ al., 2002). It is therefore possible that a person may be unfamiliar with one of the instruments included in the test. Those instruments that were not known by an individual, as determined during this preliminary step, were accounted for in the analysis of the data.

Timbre identification - part 1 (sub-test 5). A melodic pattern was played by each instrument mentioned above. Each of the instruments was presented twice in its characteristic frequency range. The only exception was the piano, which was presented once in the medium- and once in the high-frequency range. After completion of the practice items, instruments were played in random order for identification. Sufficient time was given for the individual to name the instrument that he/she thought produced the sound just heard. Test results were reported as percentages correct of those instruments known by sound as indicated in the preliminary step.

Timbre identification - part 2 (sub-test 5): This task extended the investigation of timbre perception beyond the single instrument identification task. The additional instruments present in this subtest added to the complexity of the sound. This sub-test consisted of 16 ensembles, where different combinations of the same instruments as in the previous sub-test played the same melodic piece in unison. Participants were asked to identify which of these instruments were playing together in each item. They had to rely on the timbre qualities of each instrument to identify them in the ensemble. Instruments were panned to various positions (from left to right) in the stereo field to help the participants in identifying them. A maximum of three and a minimum of two instruments played together. To minimise any unwanted effects of loudness cues, the levels of the four extracts of each instrument or ensemble were randomised over a $6 \mathrm{~dB}$ range below the participant-determined comfortable loudness level. Test results were again reported as percentage correct of those instruments known by sound as indicated in the preliminary step.

Number of instruments (sub-test 6). This sub-test determined how many different instruments participants could distinguish in a short piece of music. Participants were presented with five different instruments (cello, piccolo flute, snare drum, trumpet and xylophone) selected to have timbres as different as possible. They heard a short solo excerpt from a musical piece composed specifically for this test, played by each instrument before the onset of the actual test. Eight variations of the full piece of music (17.5 seconds in duration) played by a selection of the instruments were presented to the participants. They were asked to identify how many instruments were playing together by relying on the timbre quality and character of each instrument. Participants were required to write down the number of instruments they thought played together for each item on the answer sheet provided.

\section{Section C: Pitch}

Pitch identification (sub-test 7). This task included discrimination of complex pitch direction change. Participants were presented with pairs of two tones each, generated by a combined SawSquare wave which had been shaped by a filter to produce a synthetic tone close to that of a piano. The tones had identical spectral envelopes derived from a recorded piano note at middle $\mathrm{C}$ and uniform synthetic temporal 
envelopes to eliminate any temporal envelope cues that might be present. Each tone had a duration of $934 \mathrm{~ms}$. Each pair consisted of a base tone of F\#4/370 Hz, C3/130.8 Hz, E3/164.8 Hz or G3/196 Hz. A second tone ranging between $\mathrm{D} 4 / 293.7 \mathrm{~Hz}$ and $\mathrm{G} 5 / 784 \mathrm{~Hz}$, followed after 1.5 seconds of silence and was either higher or lower than the base tone, in a range of one semitone to 12 semitones. On each presentation, a tone at the reference frequency and a higher/lower-pitched tone were played in random order. Participants had to identify whether the second tone was higher or lower than the base tone. Each pair was separated by 5 seconds of silence.

Pitch discrimination (sub-test 8). This sub-test determined participants' ability to distinguish differences between pitch. Participants were presented with 12 pairs of short melodic sequences ( $2-5$ notes). The melodies were played on a piano in a range of C5/523.3 Hz - A7/3520 $\mathrm{Hz}$ at a tempo of 80 beats per minute. The item pairs have equivalent rhythmic patterns; however, those item pairs that are 'different' varied on one or more notes in frequency. The differences within the pairs varied from gross differences to extremely subtle differences where only a single note was flattened. The melodies in each pair were separated by 2.5 seconds of silence. Each pair was separated by 5 seconds of silence. Participants were asked to indicate whether the melodic sequences in each pair were the same or different by selecting 'Yes' if they were the same or 'No' if they were different.

\section{Section D: Melody}

Musicality perception (sub-test 9). Participants were presented with 12 pairs of short melodic sequences ( 2 - 4 bars long). The melodies were played on a piano in a range of C\#5/554.4 Hz - B6/1976 Hz at tempos ranging from 90 to 160 beats per minute. Melodies were played in various key and time signatures (4/4 and 3/4) to make the test more interesting. Some of the melodies in the pairs were random notes, making no musical sense, while others were musical pieces with a clear melodic structure. Participants had to indicate which of the melodic sequences were musical - first, second, both or none. The sequences were separated by 1.5 seconds, and each pair was separated by 5 seconds.

Melody identification (sub-test 10). To ensure that identification abilities were being assessed and not musical knowledge, each participant's familiarity with the melodies was verified before testing (Looi et al., 2008). The melodies were selected for their general familiarity from discussions among hearing and music professionals, and from earlier studies in which recognition tests demonstrated that the melodies were familiar to persons with normal hearing and cochlear implantees (Kong et al., 2005; Looi et al., 2003). To maximise cross-cultural recognition, input was also solicited from individuals of different cultural backgrounds. Ten melodies that were familiar to the South African population were included and represented a variety of melodic features, thus giving a more realistic representation of how persons with hearing aids may function across a range of items.
The melodies were played on a piano in a range of $\mathrm{A} 5 / 880 \mathrm{~Hz}$ $\mathrm{C} 8 / 4186 \mathrm{~Hz}$. The stimulus set contained two presentations of each of the 10 melodies. Each melody was first presented with its rhythmical structure intact, and then with each note having a duration of 400 milliseconds, leaving the structure of the melody intact with only pitch as a cue for melody identification (meaning that there was no rhythmical structure). The playing of the melodies was randomised, but each melody was played twice, once rhythmically intact and once not. After two practice items, participants were asked to identify the melody on both occasions from a closed set. Participants responded by writing the number corresponding to the melody title they heard on the answer sheet. Participants were allowed to request that the melodies be repeated, to a maximum of three times. The final score was reported as a percentage of correct response on the melodies with which the listener was familiar. Those items missed on the test were cross-checked with the list completed beforehand. If an item was missed, and it was not listed as familiar, that item was eliminated from the analysis. The familiarity factor is difficult to control but to limit this effect, extremely common melodies were chosen as demonstrated in Table III.

Music-in-noise song identification (sub-test 11). This sub-test aimed at providing evaluation material that is representative of real-life experiences. Well-known movie soundtracks were used. There are thousands of compositions from musical tracks used in movies from which to choose test excerpts. Because musical experiences vary considerably from one person to the next, and because recognition requires familiarity, a systematic process of selecting items that were likely to be familiar to many South Africans was used. Briefly, compositions were selected using published ranking of exposure and popularity, which offered quantifiable evidence of item exposure and familiarity to a relatively large segment of the adult South African population. Some of the included melodies have been found to be familiar by Spitzer et al. (2008), although they targeted the USA population. Table IV displays the soundtracks included.

\section{Table III. Songs included in the familiar melody identification task (sub-test 10)}
'7de Laan' theme song (theme song of a popular TV 'soap' in Nokia ring tone (popular cell South Africa)
Happy birthday to you phone ring tone in South Africa)
Jingle bells
Old MacDonald had a farm
Mary had a little lamb
Twinkle, twinkle little star
Nkosi Sikelel' iAfrica
(South African national anthem)
We wish you a merry Christmas
Wedding march (composed by Felix Mendelssohn)

\section{Table IV. Songs included in the music-in-noise song identification test (sub-test 11)}

$\begin{array}{ll}\text { Songs included in test } & \text { Film } \\ \text { Beauty and the beast } & \text { Beauty and the Beast } \\ \text { Chariots of Fire } & \text { Chariots of Fire } \\ \text { Don't cry for me, Argentina } & \text { Evita } \\ \text { I've had the time of my life } & \text { Dirty Dancing } \\ \text { Leaving on a jet plane } & \text { Armageddon } \\ \text { My heart will go on } & \text { Titanic } \\ \text { Purple rain } & \text { Purple Rain } \\ \text { Singing in the rain } & \text { Singing in the Rain } \\ \text { Unchained melody } & \text { Ghost } \\ \text { Stayin' alive } & \text { Saturday Night Fever }\end{array}$

Song titles included in list but not used as stimuli in test

A whole new world

Climb every mountain

Hungry eyes

I finally found someone

I say a little prayer for you

Diamonds are forever

Lara's theme

Pink Panther theme

Summer nights

Take my breath away
Film

Aladdin

Sound of Music

Dirty Dancing

The Mirror Has Two Faces

My Best Friend's Wedding

Diamonds are Forever

Doctor Zhivago

Pink Panther

Grease

Top Gun 
Because musical training and experience are unevenly distributed among the general population, it is possible that an individual may have no prior exposure to, and thus familiarity with, a specific item in the test, despite the fact that the excerpt is well known to the general public (Gfeller et al., 2005). Therefore, to rule out lack of prior familiarity as a factor in item recognition, an alphabetised list of melodies was included to identify the songs known by the participants. This list included 20 well-known movie soundtracks of which only 10 were included as test stimuli.

Subsequently, a simulated noisy environment, that of the interior of a car driving in traffic, was used to mask 10 of the songs. A difference of $6.2 \mathrm{~dB}$ and $10.2 \mathrm{~dB}$ was determined between the peak loudness of the music and the peak loudness of the noise which peaks at $0 \mathrm{~dB}$. Only a well-known section ( 20 seconds, with 4 -second fade in and 4-second fade out) of each song was played. The songs were separated by 10 seconds of interior car noise only. Participants were asked to identify the soundtracks presented to them by writing the corresponding number on the answer sheets. The final score was reported as a percentage of correct responses on the melodies with which the listener was familiar.

\section{General procedures}

A full-item list of the first version of the test is available in Appendix A. Most stimuli were designed specifically for this test, while stimuli for the last section were taken from commercially produced music compact discs. Each sub-test had two examples prior to the onset of the test stimuli. The following procedures were followed for all participants:

- Separate appointments were made with participants to undergo a hearing evaluation to ensure candidacy.

- The aim and procedures of the study were explained to them. Participants were also asked to provide comments regarding unclear or unnecessary procedures and questions, and to comment on the time needed to complete the MPT.

- Prior to the hearing evaluation, each participant's current hearing instruments were verified electro-acoustically to ensure that they were working properly and real-ear measurements were done to ensure that they were optimised to reflect the current best practice (Auriemmo et al., 2009).

- After the hearing evaluation had been performed, the music perception testing took place on participants who met the selection criteria. Participants were seated in an audiometric test booth, facing the speaker at 45 degrees, at a distance of approximately 1 metre. The stimuli were played on a Sony D-FJ041 audio player and presented via a Grason-Stadler GSI 61 two-channel clinical audiometer to calibrated speakers. The presentation level was 75 $\mathrm{dB}$ HL for the calibration tone. The sound level was averaged at $75 \mathrm{~dB}$ SPL and hearing-aid users were permitted to adjust the volume on their hearing aids for maximum comfort. Sound was presented at the same intensity for all hearing-aid users, regardless of individual hearing thresholds. This was done as all participants had moderate to severe hearing losses and therefore no drastic differences in audiometric thresholds were expected. The participant held an answer sheet with a set of written instructions for each test section. All instructions were also presented via the speakers before the onset of each sub-test.

- Participants completed the test at once and did not have a break between different test sections. No feedback was given during or after the test.

- After completion of the MPT, the procedures and content were discussed with the participants in order to determine whether it was relevant and whether any changes were needed.

- Participants were thanked for their time and participation.

- Data and comments were analysed and interpreted and the necessary alterations made.

The same equipment, physical set-up of the room, and instructions were used in phases 2 and 3.

\section{Reliability and validity}

Several measures were taken to increase the reliability and validity of the MPT, including (Downing \& Haladyna, 1997):
- Conducting the MPT on normal hearing listeners enabled the researcher to compile preliminary norms for this test and to compare the results of the participants with hearing loss to those of normal hearing listeners.

- Intra-rater reliability, as a form of rater reliability, ${ }^{4}$ was established as the test results were consistent when the researcher administered the test on more than one occasion.

- Test specifications were constructed by documentation of specifications for the test and can be seen in the MPT manual available in Appendix B.

- Item content verification was done by providing a reference list of sources used in the development of the test as well as a peer content review. The peer content review was employed in the form of a rating scale to classify the quality of items included, as well as the relevance of the test to the field being assessed. The evaluation sheet for the peer content review was given to four independent audiologists and three music teachers. A copy of evaluation sheet used for the peer content review can be found in Appendix C. Various aspects were addressed in the music perception test evaluation sheet and after completion by professionals in the audiology and music industry provided the MPT with face validity, ${ }^{5}$ content validity, ${ }^{6}$ construct validity ${ }^{7}$ and criterion validity $^{8}$ (Shipley \& McAfee, 2004).

- Test item editing was done in phase 2 where items with high error rates were dismissed. By reviewing items, the clarity and appearance of items were enhanced. Furthermore, all items that needed editing were professionally edited.

- Revision to identify bias-sensitivity as one source of invalidity may be measurement error introduced by the language used. A thorough and systematic review of the MPT for potentially biased words, phrases, situations or content was done in order to eliminate potentially culturally biased words, phrases and situations that might be offensive to some individuals or groups. This was done by including individuals from different ethnic groups in the peer review. An exact match of the South African demographics could not be obtained, but Downing and Haladyna (1997) indicated that an exact match to the demographics of the target examinees is unnecessary.

- Test security of items was ensured. This is essential as invalidity is introduced to the test if some examinees have access to test items whereas others do not. Furthermore, the researcher ensured that the examination was secure and that careful documentation, record keeping and a method of systematic, routine reporting of documentation took place.

\section{Data analysis}

Test scores from the MPT were directly written on the answer sheet. Each answer sheet was marked with the respondent's number to ensure participant anonymity. All the answer sheets were checked to ensure that they had been completed in full before participants left the practice. The answer sheets were hand-scored because some melodies have both alternative and well-known titles and there are often multiple versions of lyrics. Furthermore, individual assessment of sub-test 5 (parts 1 and 2 ), sub-test 10 and sub-test 11 was required because in these sub-tests participants were only assessed on items familiar to them and therefore the total for each of these sub-tests differed for all participants. The researcher transferred all the data from the answer sheets into a Microsoft Excel work sheet. Responses were quantitatively coded and analysed with computer software. Data were processed with the use of an HP Intel Core $23.0 \mathrm{GHz}$ processor and Microsoft Windows Vista as well as Microsoft Office programmature.

4 Refers to the degree to which the same person or different people obtain the same or very similar results after administering a tes.

5 This implies that the MPT appears to measure what it claims to measure based on appearance. 6 This refers to the completeness of the MPT as a valid assessment of music perception because of the whole spectrum of skills that were tested.

7 This refers to the MPT's ability to measure predetermined theoretical construct, in this case music perception, which is an explanation of behaviour based on empirical observations. 8 This implies validity of the MPT that is established by the use of external criteria as obtained from the peer review. 


\section{Results}

\section{Phase 2: Normal hearing participants}

Participants obtained an average score of $88.8 \%$ for the rhythm section of the test with individual scores ranging between $70 \%$ and $100 \%$. For the timbre section, a group average of $74.1 \%$ was obtained while participants' scores ranged between $54 \%$ and $92 \%$. An average score of $75.9 \%$ was obtained for the pitch section, with a range of $50-100 \%$. The average score for the melody section of the test was $78.8 \%$ (range $63-93 \%)$. These results are summarised in Table V.

From Table $\mathrm{V}$ it is evident that participants performed best on the rhythm section of the MPT, with the highest average score obtained for the rhythm identification task. The worst performance was for the timbre section of the MPT, while the lowest average group score was obtained for the pitch discrimination task. Three errors on any single item were defined on a practical basis as a high error rate for normal hearing listeners (20\% of the sample). Spitzer et al. (2008) previously used a high error rate as $15 \%$ of the sample got a certain item wrong. Test 1 had only 1 item with a high error rate while 2 items in test 2 were found to have a high error rate, 3 items in test 3 and 5 items in test 4 . In test 5 (part 1), 7 items were found to have a high rate of error and 13 items in test 5 (part 2). Test 6 had 4 items, test 7 had 2 items and test 8 had 11 items with a high error rate. Nine items in test 9, 14 items in test 10 and 1 item in test 11 had high error rates. All items with high error rates were either adapted or eliminated in constructing the second version of the test that was used in phase 3 .

\section{Phase 2: Participants with hearing aids}

Hearing-aid users obtained an average score of $73.5 \%$ for the rhythm section, $51.2 \%$ for the timbre section, $67.7 \%$ for the pitch section and $40.2 \%$ for the melody section of the MPT. Individual scores ranged between $48 \%$ and $100 \%$ for the rhythm section, $23 \%$ and $87 \%$ for the timbre section, $48 \%$ and $100 \%$ for the pitch section and $0 \%$ and $92 \%$ for the melody section of the test. The results of the participants with hearing aids included in phase 2 are summarised in Table VI.

Table VI shows that hearing-aid users also performed best on the rhythm section of the MPT with the highest average score again obtained for the rhythm identification task. The worst performance was on the melody section, probably due to the extremely low score obtained for the music-in-noise song identification task. From the results obtained in phase 2 , the following major changes were made to the test:

- To shorten the test, most of the sections were reduced from 12 to 10 items. The items eliminated in each section were those that were found to have the highest error rates. By shortening the test the reliability was increased as the probability of poor results caused by length of concentration and fatigue are reduced.

- $\quad$ For test 5 (part 2), the difficulty of the test items was addressed. Most items consisted of 3 musical instruments playing together. Participants were unable to identify 3 instruments correctly, but could identify 1 or 2 instruments playing in an ensemble. Stimuli were therefore changed so that most items included only 2 instruments with only a few items remaining more difficult (3 instruments).

- The same principle was followed in test 6 . The degree of difficulty was reduced by including fewer musical instruments playing together; the items with high error rates were those where 4 or 5 instruments had been combined.

- A decrease in participants' scores was noted for test 8. This was found to be unrelated to difficulty of the test items; it was due to unclear instructions. Participants mentioned that they were unclear of what was expected of them. Therefore the test items were left unchanged with only the 2 items with the highest error rates being eliminated. Focus was placed on changing the instructions to avoid misunderstanding.

- The analysis of the results of test 10 showed that participants confused 2 of the items which sounded very similar. The first few notes of 'Baa baa black sheep' and 'Twinkle, twinkle little star' are almost identical. Confusing of these two melodies caused the percentage of success on this task to drop by $16.7 \%$ ( 2 melodies each being presented twice). It was therefore decided to eliminate one of these melodies to avoid unnecessary confusion. The items with the highest error rate were also eliminated to reduce the number of test items to 20 instead of 24 .

- Test 11 was not found to be problematic with the normal hearing participants, but almost all of the hearing-aid users obtained no score for this test. All of the hearing-aid users complained that the background noise was too loud and that they were unable to hear the melody. Therefore the stimuli were changed by reducing the intensity of the noise compared with that of the melody.

Table V. Error rates and percentage correct for the first version of the MPT presented to normal hearing participants $(n=15)$

\begin{tabular}{|c|c|c|c|c|}
\hline Musical category & Test section & $\begin{array}{l}\text { Maximum \# responses } \\
(\# \text { items } \times n)\end{array}$ & $\begin{array}{l}\text { Group total } \\
\text { errors }\end{array}$ & $\begin{array}{l}\text { Group total } \\
\text { correct (\%) }\end{array}$ \\
\hline \multirow{4}{*}{ Rhythm } & 1. Rhythm identification & $12 \times 15=180$ & 13 & $167(92.8 \%)$ \\
\hline & 2. Rhythm discrimination & $12 \times 15=180$ & 14 & $166(92.2 \%)$ \\
\hline & 3. Rhythm recognition & $12 \times 15=180$ & 24 & $156(86.7 \%)$ \\
\hline & 4. Rhythm perception & $12 \times 15=180$ & 30 & $150(83.3 \%)$ \\
\hline \multirow{3}{*}{ Timbre } & 5a. Single instrument identification & $\begin{array}{l}16 \times 15=240 \\
\text { Actual max: } 223^{*}\end{array}$ & 43 & $180(80.7 \%)$ \\
\hline & 5b. Multiple instrument identification & $\begin{array}{l}16 \times 15=240 \\
\text { Actual max: } 202^{*}\end{array}$ & 47 & $155(76.7 \%)$ \\
\hline & 6. Number of instruments & $8 \times 15=120$ & 42 & $78(65 \%)$ \\
\hline \multirow{2}{*}{ Pitch } & 7. Pitch identification & $12 \times 15=180$ & 20 & $160(88.9 \%)$ \\
\hline & 8. Pitch discrimination & $12 \times 15=180$ & 67 & $113(62.8 \%)$ \\
\hline \multirow{3}{*}{ Melody } & 9. Musicality perception & $12 \times 15=180$ & 50 & $130(72.2 \%)$ \\
\hline & 10. Melody identification & $\begin{array}{l}24 \times 15=360 \\
\text { Actual max: } 360^{*}\end{array}$ & 99 & $261(72.5 \%)$ \\
\hline & 11.Music-in-noise song identification & $\begin{array}{l}12 \times 15=180 \\
\text { Actual max: } 159^{*}\end{array}$ & 13 & $146(91.8 \%)$ \\
\hline
\end{tabular}


Table VI. Error rates and percentage correct for the first version of the MPT presented to participants with hearing aids $(n=4)$

\begin{tabular}{|c|c|c|c|c|}
\hline Musical category & Test section & $\begin{array}{l}\text { Maximum \# responses } \\
(\# \text { items } \times n)\end{array}$ & $\begin{array}{l}\text { Group total } \\
\text { errors }\end{array}$ & $\begin{array}{l}\text { Group total } \\
\text { correct (\%) }\end{array}$ \\
\hline \multirow[t]{4}{*}{ Rhythm } & 1. Rhythm identification & $12 \times 4=48$ & 6 & $42(87.5 \%)$ \\
\hline & 2. Rhythm discrimination & $12 \times 4=48$ & 12 & $36(75.0 \%)$ \\
\hline & 3. Rhythm recognition & $12 \times 4=48$ & 16 & 16 \\
\hline & 4. Rhythm perception & $12 \times 4=48$ & 17 & $31(64.6 \%)$ \\
\hline \multirow[t]{3}{*}{ Timbre } & 5a. Single instrument identification & $\begin{array}{l}16 \times 4=64 \\
\text { Actual max: } 50^{*}\end{array}$ & 27 & $23(54.0 \%)$ \\
\hline & 5b. Multiple instrument identification & $\begin{array}{l}16 \times 4=64 \\
\text { Actual max: } 34^{*}\end{array}$ & 15 & $19(55.9 \%)$ \\
\hline & 6. Number of instruments & $8 \times 4=32$ & 18 & $14(43.8 \%)$ \\
\hline \multirow[t]{2}{*}{ Pitch } & 7. Pitch identification & $12 \times 4=48$ & 11 & $37(77.1 \%)$ \\
\hline & 8. Pitch discrimination & $12 \times 4=48$ & 20 & $28(58.3 \%)$ \\
\hline \multirow[t]{3}{*}{ Melody } & 9. Musicality perception & $12 \times 4=48$ & 18 & $30(62.5 \%)$ \\
\hline & 10. Melody identification & $\begin{array}{l}24 \times 4=96 \\
\text { Actual max: } 76^{*}\end{array}$ & 32 & $44(57.9 \%)$ \\
\hline & 11. Music-in-noise song identification & $\begin{array}{l}12 \times 4=48 \\
\text { Actual max: } 17^{*}\end{array}$ & 16 & $1(0.06 \%)$ \\
\hline
\end{tabular}

*Actual maximum for test differs from maximum possible responses as participants indicated with which items they were familiar and the final score was reported as a percentage of correct responses on the items with which the listener was familiar.

Furthermore, the 2 items with the highest error rates were eliminated to reduce the number of items to 10.

- Technical adjustments and language editing were done to improve the test and reduce confusion.

The second version (Appendix D) of the MPT consisted of the same sections as the first version but most of the sections were shorter to reduce the length of the test. This version of the MPT was constructed with a total of 140 items (test 1, 2, 3, 4, 7, 8, 9=10 items each, test 5 (part one) $=16$ items, test 5 (part two $)=16$ items, test $6=8$ items, test $10=20$ items and test $11=10$ items). A marking sheet of all the answers of the revised version of the test can be seen in Appendix E.

In phase 3, the adapted version of the MPT was presented to 4 adults with normal hearing and 20 adults with hearing aids. Scores for the different sections of the test improved on presentation to the adults with normal hearing when compared with the results of normal hearing listeners in phase 2, as can be seen in Table VII. Normal hearing participants obtained an average score of $93.8 \%$ for the rhythm section of the test with individual scores ranging between $80 \%$ and $100 \%$. For the timbre

\section{Table VII. Error rates and percentage correct for the adapted version of the MPT presented to normal hearing} listeners $(n=4)$

\begin{tabular}{|c|c|c|c|c|}
\hline Musical category & Test section & $\begin{array}{l}\text { Maximum \# responses } \\
(\# \text { items } \times n)\end{array}$ & Group total errors & Group total correct (\%) \\
\hline \multirow[t]{4}{*}{ Rhythm } & 1. Rhythm identification & $10 \times 4=40$ & 2 & $38(95.0 \%)$ \\
\hline & 2. Rhythm discrimination & $10 \times 4=40$ & 1 & $39(97.5 \%)$ \\
\hline & 3. Rhythm recognition & $10 \times 4=40$ & 3 & $37(92.5 \%)$ \\
\hline & 4. Rhythm perception & $10 \times 4=40$ & 4 & $36(90.0 \%)$ \\
\hline \multirow[t]{3}{*}{ Timbre } & 5a. Single instrument identification & $\begin{array}{l}16 \times 4=64 \\
\text { Actual max: } 60\end{array}$ & 8 & $52(86.7 \%)$ \\
\hline & 5b. Multiple instrument identification & $\begin{array}{l}16 \times 4=64 \\
\text { Actual max: } 53^{*}\end{array}$ & 10 & $43(81.1 \%)$ \\
\hline & 6. Number of instruments & $8 \times 4=32$ & 6 & $26(81.3 \%)$ \\
\hline \multirow[t]{2}{*}{ Pitch } & 7. Pitch identification & $10 \times 4=40$ & 3 & $37(92.5 \%)$ \\
\hline & 8. Pitch discrimination & $10 \times 4=40$ & 8 & $32(80.0 \%)$ \\
\hline \multirow[t]{3}{*}{ Melody } & 9. Musicality perception & $10 \times 4=40$ & 7 & $33(82.5 \%)$ \\
\hline & 10. Melody identification & $\begin{array}{l}20 \times 4=80 \\
\text { Actual max: } 80^{*}\end{array}$ & 8 & $72(90.0 \%)$ \\
\hline & 11. Music-in-noise song identification & $\begin{array}{l}10 \times 4=40 \\
\text { Actual max: } 38^{*}\end{array}$ & 3 & $35(92.1 \%)$ \\
\hline
\end{tabular}


section a group average of $83 \%$ was obtained while participants' scores ranged between $66 \%$ and $100 \%$. An average score of $86.3 \%$ was obtained for the pitch section and $88.2 \%$ for the melody section of the test. For the pitch section scores ranged between $70 \%$ and $100 \%$ while scores ranged between $68 \%$ and $100 \%$ for the melody section.

Again, the best average score was obtained for the rhythm section of the test while the lowest average score was obtained for the timbre section. The task with the highest score was the rhythm discrimination task whereas the pitch discrimination task obtained the lowest average score.

Results of phase 3, in which the test items were administered to hearing-aid users, are summarised in Table VIII. In this phase, hearingaid users obtained an average score of $75.5 \%$ for the rhythm section, $62.3 \%$ for the timbre section, $70.8 \%$ for the pitch section and $61.9 \%$ for the melody section of the MPT. Individual scores ranged between $60 \%$ and $100 \%$ for the rhythm section, $46 \%$ and $94 \%$ for the timbre section, $60 \%$ and $100 \%$ for the pitch section and $39 \%$ and $100 \%$ for the melody section of the test.

From Table VIII it is evident that hearing-aid users performed the best on the rhythm section of the test and obtained the highest score for the rhythm identification task. Again these listeners obtained the lowest average score for the timbre section of the test with the identification of multiple instruments being the most difficult task.

The mean overall score for the hearing-aid users who completed the adapted version of the MPT was $68.6 \%$. Figure 2 illustrates the overall individual performances on the MPT for this group.

With a bigger, heterogeneous group of hearing-aid users who completed the revised version of the test, a few observations were made. First, the entire sample was able to perform all the different sub-tests of the MPT. None of the participants was confused by the tasks or unable to participate. Table VIII reflects that all the participants found tests 1, 2, 3 and test 4 relatively easy and performed fairly well on these tasks, obtaining an average score of $60 \%$ or more. Results for test 5 (parts one and two) were somewhat different and are presented in Figures 3 and 4. As demonstrated in Figure 3, just over half of the participants (11 of 20) found this task relatively easy and obtained a score of $60 \%$ or more while the other 9 participants' scores ranged from $25 \%$ to $56 \%$.

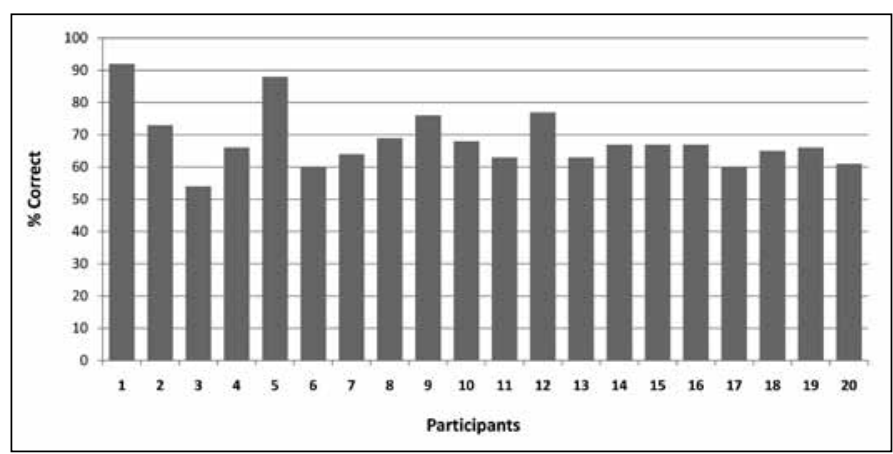

Fig. 2. The overall individual performances of hearing-aid users on the adapted version of the MPT.

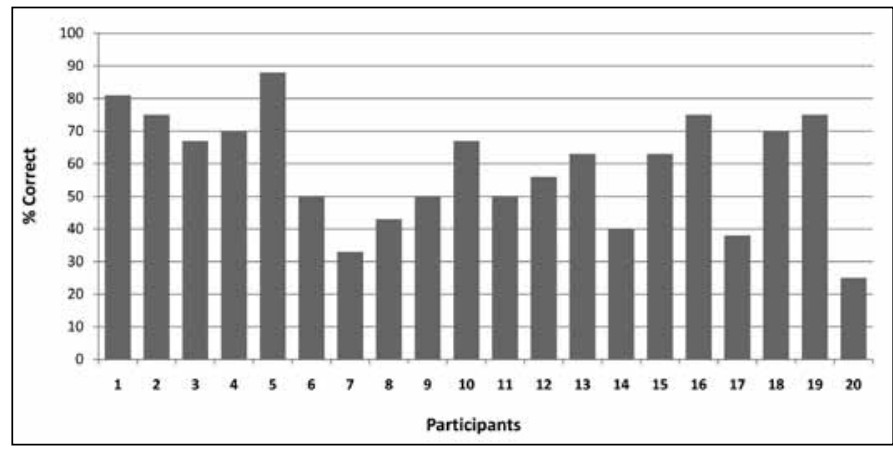

Fig. 3. Participants' performance on the single instrument identification task (test 5, part one).

It was noted that participants who performed better on this task were those who indicated that they were able to play one or more musical instruments or had some formal musical training.

Figure 4 displays participants' individual performance on the multiple instrument identification task (test 5 , part 2).

The scores displayed in Figure 4 indicate that participants obtained much lower scores for this task than the previous one. It was, however,

\section{Table VIII. Error rates and percentage correct for the adapted version of the MPT presented to participants} with hearing aids $(n=20)$

\begin{tabular}{|c|c|c|c|c|}
\hline Musical category & Test section & $\begin{array}{l}\text { Maximum \# responses } \\
(\# \text { items } \times n)\end{array}$ & Group total errors & Group total correct $(\%)$ \\
\hline \multirow[t]{4}{*}{ Rhythm } & 1. Rhythm identification & $10 \times 20=200$ & 31 & $169(84.5 \%)$ \\
\hline & 2. Rhythm discrimination & $10 \times 20=200$ & 46 & $154(77.0 \%)$ \\
\hline & 3. Rhythm recognition & $10 \times 20=200$ & 43 & $157(78.5 \%)$ \\
\hline & 4. Rhythm perception & $10 \times 20=200$ & 76 & $124(62.0 \%)$ \\
\hline \multirow[t]{3}{*}{ Timbre } & 5a. Single instrument identification & $\begin{array}{l}16 \times 20=320 \\
\text { Actual max: } 196^{*}\end{array}$ & 80 & $116(59.2 \%)$ \\
\hline & 5b. Multiple instrument identification & $\begin{array}{l}16 \times 20=320 \\
\text { Actual } \mathrm{m} \text { ax: } 119^{*}\end{array}$ & 55 & $64(53.8 \%)$ \\
\hline & 6. Number of instruments & $8 \times 20=160$ & 42 & $118(74.0 \%)$ \\
\hline \multirow[t]{2}{*}{ Pitch } & 7. Pitch identification & $10 \times 20=200$ & 52 & $148(74.0 \%)$ \\
\hline & 8. Pitch discrimination & $10 \times 20=200$ & 65 & $135(67.5 \%)$ \\
\hline \multirow[t]{3}{*}{ Melody } & 9. Musicality perception & $10 \times 20=200$ & 91 & $109(54.5 \%)$ \\
\hline & 10. Melody identification & $\begin{array}{l}20 \times 20=400 \\
\text { Actual max: } 328^{*}\end{array}$ & 105 & $223(68.0 \%)$ \\
\hline & 11. Music-in-noise song identification & $\begin{array}{l}10 \times 20=200 \\
\text { Actual max: } 87^{\star}\end{array}$ & 32 & $55(63.2 \%)$ \\
\hline
\end{tabular}

*Actual maximum for test differs from maximum possible responses as participants indicated with which items they were familiar and the final score was reported as a percentage of correct responses on the items with which the listener was familiar. 


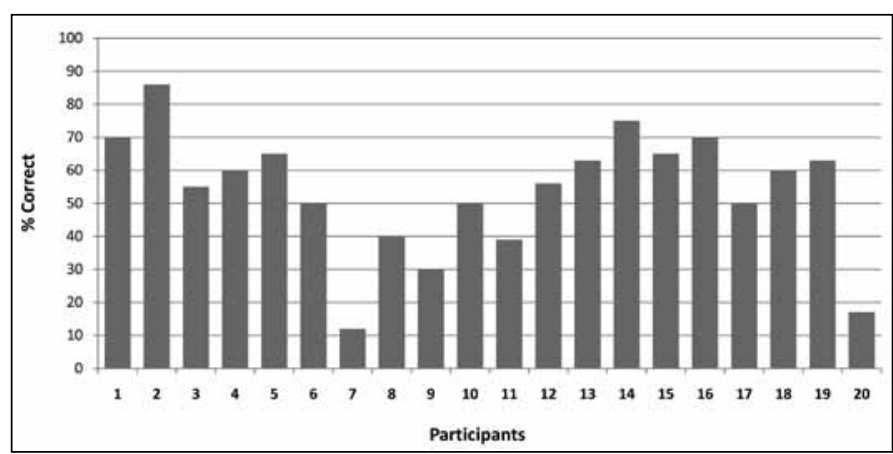

Fig. 4. Participants' performance on the multiple instrument identification task (test 5 , part 2).

expected that participants would find this task more difficult than the previous one as the combination of instruments were included as a task of increased difficulty to assess timbre recognition beyond single instruments. Furthermore, it is evident that 65\% (13 of 20) of the participants obtained lower scores for the multiple instrument identification task compared with the single instrument identification task, with only $15 \%$ (3 of 20) of participants scoring exactly the same on both tasks. A total of $20 \%$ ( 4 of 20) of the participants had improved scores on the more challenging task, possibly because they had musical training. For 1 of the 4 participants the improvement was very slight (only 2\%), but for the other 3 improvement of $11 \%, 35 \%$ and $12 \%$ was seen. This improvement was not expected and warrants further investigation. Interstingly, when asked what they thought contributed to their superior performance in this task, 3 of them replied that they regularly listen to classical music and therefore found the identification of instruments presented in an ensemble not that difficult. This can be explained by the fact that classical compositions consist of complex harmonic progressions, intricate rhythms and timbral blends (Gfeller et al., 2005) and should be investigated in more detail.

Results of test 6 , test 7, test 8 , test 10 and test 11 were all relatively good, with the average for all of these tasks being $60 \%$ or above. The range of scores for these tests were:

- $\quad$ Test 6 - number of instruments

- $\quad$ Test 7 - pitch identification

- Test 8 - pitch discrimination

$29-100 \%$

$50-100 \%$

$50-100 \%$

- Test 10 - melody identification

$0-90 \%$

- $\quad$ Test 11 - music-in-noise song identification

$0-100 \%$

Participants obtained a lower average score for the musicality perception task (test 9). These data are displayed in Figure 5.

From Figure 5 it seems that participants found the musicality perception task challenging as they only obtained an average score of $54.5 \%$ for this task. This task again has a correlation with musicality and therefore explains the tendency of participants with previous musical training to perform better than participants with no musical training.

\section{Discussion and conclusion}

The development of a musical test for hearing-aid users, in which there is a stepwise, graded range of difficulty, was feasible, based on the

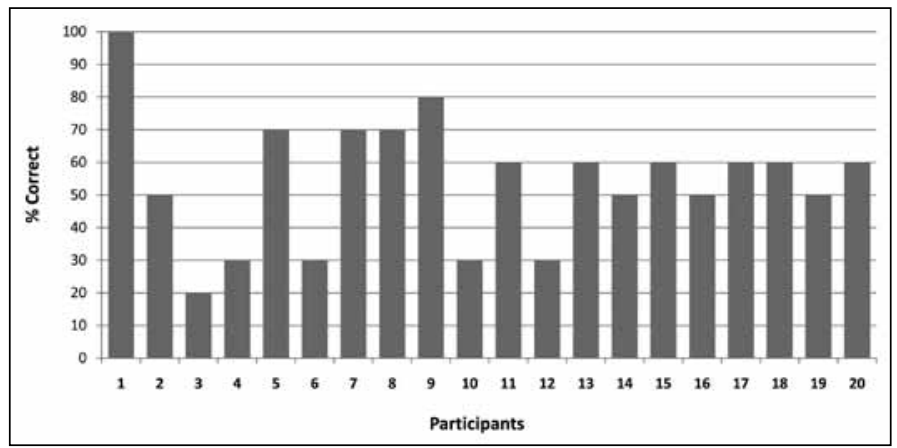

Fig. 5. Participants' performance on the musicality perception task (test 9). present findings. Test results of the MPT demonstrated that each section entailed a different challenge level and that various difficulty levels were included in each section. This is important as it demonstrates that the MPT was neither too easy nor too difficult for hearing aid users and therefore implies that valid results will be obtained; the difficulty level of the test will make it possible for most hearing-aid users to complete. Furthermore, results proved that normal hearing adults as well as adults with hearing aids were able to complete all the sub-tests of the MPT although hearing-aid users obtained lower scores on the various subtests compared with normal hearing listeners.

Although hearing-aid users scored less than normal hearing users on the rhythm section of the MPT, they still obtained relatively high scores. The high scores obtained by hearing aid users on the rhythm tasks are not unexpected as it is known that adults with hearing loss increase their reliance on temporal cues as their hearing loss increases. This reliance on temporal cues is logical, given that, for most severe hearing losses, frequency resolution is lost, while temporal information remains largely intact (Flynn, Davis \& Pogash, 2004). Furthermore, previous research confirmed that adults with hearing loss generally perceive rhythm as well as adults with normal hearing (Looi et al., 2008). The poor performance on the timbre perception might be explained by the fact that accurate timbre perception requires the perception of both the signal's temporal envelope and the energy spectrum of its harmonic components. Modifying features of the temporal envelope or changing the frequencies and/or amplitude of the harmonic components could alter the timbre perceived (Looi et al., 2008). Therefore, the comparatively poorer identification results for participants with a hearing loss compared with normal hearing participants might suggests that the hearing aid does not sufficiently transmit the broad spectral envelope and/or temporal envelope information from the input signal to enable accurate timbral perception. This may have arisen from a range of factors. For a normal hearing individual, such spectral selectivity derives from the different frequency components of the acoustic stimulus being separated into different auditory filters, with each frequency component resulting in activity at discrete sites along the basilar membrane. For hearing-aid users, perceptual smearing may occur as a consequence of auditory filter anomalies associated with cochlear hearing loss, poor neural survival patterns, and poor frequency selectivity. This may result in diminishing spectral clarity of the stimuli for the subject (Looi et al., 2008).

As it is well known that cochlear damage leads to changes in perceived pitch or reduced pitch perception accuracy (Ricketts, Dittberner \& Johnson, 2008; Moore, 1996), it was expected that hearing-aid users would obtain lower scores on pitch-related tasks than normal hearing listeners. This might be due to the that fact that people with cochlear damage depend relatively more on temporal information and less on spectral information than normal hearing listeners when perceiving pitch (Moore, 1996). Performance on the melody section of the test can be similarly explained as listeners depend on exact pitch intervals of melodies when trying to recognise them. Gfeller and Lansing (1992) also confirmed that hearing loss has a significant impact on melody perception; therefore it was not unexpected for normal hearing adults to perform better on melodic perception tasks than hearing-aid users. As previously mentioned, currently no MPTs for hearing-aid users exist, as most of the previously designed MPTs were compiled with cochlear implantees as the target population. Therefore results of the current test could not be compared with results obtained in previous studies.

The different sections of the MPT were intended to provide an insight into different aspects of music perception. The possible value of using a test like this in the hearing-aid industry can result in more effective hearing-aid fittings taking place, specifically with the focus being placed on music perception. The test can further be used as a counselling tool to assist audiologists and patients in understanding the problems they experience regarding music perception, and might be used for future musical training in areas where participants experience problems in customising individual fittings. 
The use of a test such as the MPT may also have pitfalls. Most notably, there is a cultural specificity to the items selected (Spitzer et al., 2008). Familiarity with melodies may be affected by access, both on the basis of national origin as well as listening experiences resulting from hearing loss or other factors (Spitzer et al., 2008). The MPT should probably be used with caution when the test participant is not originally from South Africa or has not stayed in South Africa for long, as this might imply that the person could be unfamiliar with some of the stimuli included in the test. Furthermore very early onset of hearing loss may effectively eliminate the ability to respond to certain sections of this test, as persons with a pre/perilingual onset of hearing loss might not have a reference for some of the musical stimuli used in this test. Those sections can be eliminated as persons with a pre/perilingual onset of deafness will indicate that they are unfamiliar with certain items, and participants are only evaluated on items with which they indicate they are familiar. Another issue is that the ability to perform well on the MPT does not imply musical satisfaction. The impact of alterations in hearing-instrument settings and characteristics designed to enhance musical perceptual performance or satisfaction are major areas that remain important for additional investigation (Spitzer et al., 2008).

As the purpose of examining a hearing-aid user sample was to demonstrate that participants using hearing aids can perform the MPT tasks, we do not draw larger conclusions here about the performance of hearing-aid users in general. However, to use the MPT effectively in the South African context, it should be performed on a large group of adults in order to determine norms for the test as one of the limitations of the current study was the inclusion of limited participants and therefore only preliminary norms were established. Furthermore, the current study only included participants who were proficient and literate in English. Future studies should perform the MPT on a sample that is representative of South Africa's demographics. Participants of all ethnic groups should be included in research with the aim of using a newly developed test and gathering of normative data for such a test. Future studies might also examine the performance of children on the MPT to determine whether the test could be used successfully for assessment of music perception in children with hearing aids. As there is however no South African MPT available to date, this study contributes towards knowledge in this field and assists audiologists to provide evidencebased services to their music-loving clients as the MPT can be used as data-acquisition material in future hearing-aid studies. It also serves as background for future research in this field.

Currently, about one-sixth of South Africa's population experience a hearing disability (Statistics South Africa, 2001) and this number is likely to increase due to an increase in environmental noise (O'Neill, Summer \& Shirey, 1999), increased use of personal listening devices and increase in life expectancy (Eureka Science News, 2008). These alerting statistics emphasise the importance of further research in this context to better understand the influence of hearing loss on people's lives and to ensure optimal hearing-aid use in all situations. Furthermore, it has been found that improving consistency of communication success (through amplification) narrows the discrepancy in stress levels experienced; a survey conducted in the New York Times showed that $64 \%$ of the general population listened to music to relax (Kuk \& Peeters, 2008). It is therefore incumbent upon health care professionals, including audiologists, to understand how music has an effect on the overall well-being of people so that we, as a profession, may do our best to ensure the consistent and convenient use of music by people with a hearing loss for entertainment as well as for therapeutic benefits.

This paper has not been presented at any professional meetings.

\section{References}

Auriemmo, J., Kuk, F., Lau, C., Marshall, S., Thiele, N., Pikora, M., Quick, D., \& Stenger, P. (2009). Effect of linear frequency transposition on speech recognition and production of school-age children. Journal linear frequency transposition on speech recognition
of the American Academy of Audiology 20(5): 289-305.

Bagatto, M., Scollie, S., Glista, D., Parsa, V., \& Seewald, R. (2008). Case study: Outcomes of hearing impaired listeners using nonlinear frequency compression technology. Retrieved on 8 September 2010 from http:// wwwaudiologyonline.com/article detail.asp?article_id $=1990$

Babbie, E. (2002). The practice of social research. California, USA: Wadswort.

Barab, S., \& Squire, K. (2004). Design-based research: putting a stake in the ground. The Journal of Learning Sciences 13(1): 1-14.
Cairns, S., Frith, R., Munro, K.J., \& Moore, B.C.J. (2007). Repeatability of the TEN(HL) test for detecting cochlear dead regions. International Journal of Audiology 46(10): 575-584.

Chasin, M. (2010). Amplification fit for music lovers. Hearing Journal 63(9): 27-30.

Chasin, M. (2004). Hear the music ... or not? Hearing Journal 57(7): 10-16.

Chasin, M., \& Russo, F.A. (2004). Hearing aids and music. Trends in Amplification 8(2): 35-47.

Chasin, M. (2003). Music and hearing aids. Hearing Journal 56(7): 36-41.

Cooper, W.B., Tobey, E., \& Loizou, P.C. (2008). Music perception by cochlear implant and normal hearing listeners as measured by the Montreal Battery for Evaluation of Amusia. Ear and Hearing 29(4): 618-626.

Cross, I. (2006). The origins of music: Some stipulations on theory. Music Perception 24(1): 79-81.

Don, A.J., Schellenberg, E.G., \& Rourke, B.P. (1999). Music and language skills of children with Williams syndrome Child Neuropsychology 5(3): 154-170.

Downing, S.M., \& Haladyna, T.M. (1997). Test item development: Validity evidence from quality assurance procedures. Applied Measurement in Education 10(1): 61-82.

Eureka! Science News. (2008). Study examines prevalence of hearing loss in the United States. Retrieved on 15 March 2009 from http://esciencenews.com/articles/2008/07/28/study.examines.prevalence.hearing.loss.us

Flynn, M.C., Davis, P.B., \& Pogash, R. (2004). Multiple-channel non-linear power hearing instruments for childre with severe hearing impairment: Long-term follow-up. International Journal of Audiology 3(8): 479-485.

Fujita, S., \& Ito, J. (1999). Ability of nucleus cochlear implantees to recognize music. Annals of Otology, Rhinology and Laryngology 108: 634-640.

Gfeller, K., Olszewski, C., Rychener, M., Sena, K., Knutson, J.F., Witt, S., \& Macpherson, B. (2005). Recognition of 'real-world' musical excerpts by cochlear implant recipients and normal-hearing adults. Ear and Hearing 26(3): $237-250$

Gfeller, K., Witt, S., Adamek, M., Mehr, M., Rogers, J., Stordahl, J., \& Ringgenberg, J. (2002). Effects of training on timbre recognition and appraisal by postlingually deafened cochlear implant recipients. Journal of the American Academy of Audiology 13(3): 132-145.

Gfeller, K., Turner, C., Mehr, M., Woodworth, G., Fearn, R., Knutson, J.F., Witt, S., \& Stordahl, J. (2002). Recognition of familiar melodies by adult cochlear implant recipients and normal-hearing adults. Cochlear Implants International 3(1): 29-53.

Gfeller, K., Woodworth, G., Robin, D.A., Witt, S., \& Knutson, J.F. (1997). Perception of rhythmic and sequentia pitch patterns by normally hearing adults and adult cochlear implant users. Ear and Hearing 18(3): 252-260.

Gfeller, K., \& Lansing, C.R. (1991). Melodic, rhythmic, and timbral perception of adult cochlear implant users. Journal of Speech and Hearing Research 34: 916-920.

Gfeller, K., \& Lansing, C. (1992). Musical perception of cochlear implant users as measured by the primary measures of music audiation: An item analysis. Journal of Music Therapy 29(1): 18-39.

Glista, D., \& McDermott, H. (2008). Phonak SoundRecover: A breakthrough in enhancing intelligibility. Naida Product Information. Stafa, Switzerland: Phonak Hearing Systems.

lakovides, S.A., Iliadou, V.T.H., Bizeli, V.T.H., Kaprinis, S.G., Fountoulakis, N., \& Kaprinis, G.S. (2004) Psychophysiology and psychoacoustics of music: Perception of complex sound in normal subjects and psychiatric patients. Annals of General Hospital Psychiatry 3: 1-4.

Jenkins, S., Price, C., \& Starker, L. (2003). The researching therapist. Edinburgh: Churchill Livingstone.

Kong, Y., Stickney, G., \& Zeng, F.G. (2005). Speech and melody recognition in binaurally combined acoustic and electric hearing. Journal of the Acoustical Society of America 117(3): 1351-1361.

Kreutz, G., Schubert, E., \& Mitchell, L.A. (2008). Cognitive styles of music listening. Music Perception 26(1): 57-73.

Kuk, F., Keenan, D., Korhonen, P., \& Lau, C. (2009). Efficacy of linear frequency transposition on consonan identification in quiet and in noise. Journal of the American Academy of Audiology 20(8): 465-479.

Kuk, F., \& Peeters, H. (2008). The hearing aid as a music synthesizer. Hearing Review October 2008. Retrieved on 3 May 2009 from http://www.hearingreview.com/issues/articles/2008-10_03.asp

Leal, M.C., Shin, Y.J.E., Laborde, M.L., Calmels, M., Verges, S., Lugardon, S., Andrieu, S., Deguine, O., \& Fraysse, B. (2003). Music perception in adult cochlear implant recipients. Acta Oto-laryngologica 123: 826-835.

Leedy, P.D., \& Ormrod, J.E. (2005). Practical research: Planning and design. 8th ed. New Jersey: Courier Kendallville

Looi, V., McDermott, H., McKay, C., \& Hickson, L. (2008). Music perception of cochlear implant users compared with that of hearing aid users. Ear and Hearing 2 (3): 421-434.

McDermott, H.J., \& Dean, M.R. (2000). Speech perception with steeply sloping hearing loss: effects of frequency transposition. British Journal of Audiology 34(6): 353-361.

Medel Medical Electronics. (2006). MuSIC Perception Test User Guide. United Kingdom: H \& D Fitzgerald.

Moore, B.C.J. (1996). Perceptual consequences of cochlear hearing loss and their implications for the design of hearing aids. Ear and Hearing 17(2): 133-161.

Moore, B.C.J. (2009). Dead zones: What are they and what do you do about them? Hearing Journal 62(3): 10-17.

Moore, B.C.J., \& Alcantara, J.I. (2001). The use of psychophysical tuning curves to explore dead regions in the cochlea. Ear and Hearing 22(4): 268-278.

Munro, K.J. (2007). Integrating cochlear dead region diagnosis into the hearing instrument fitting process. Phonak Focus 38: 1-19.

Nimmons, G.L., Kang, R.S., Drennan, W.R., Longnion, J., Ruffin, C., Worman, T., Yueh, B., \& Rubinstein, J.T. (2008). Clinical assessment of music perception in cochlear implant listeners. Otology \& Neurotology 29(2): $149-155$.

Nyffeler, M. (2008). Study finds that non-linear frequency compression boosts speech intelligibility. Hearing Journal 61(12): 22-24.

O'Neill, G., Summer, L., \& Shirey, L. (1999). Hearing loss: A growing problem that affects quality of life. Challenge for the 21st Century: Chronic and Disabling Conditions 2: 1-6.

Plante, E., \& Beeson, P.M. (1999). Communication and Communication Disorders: A Clinical Introduction. Boston Massachusetts: Allyn \& Bacon.

Ricketts, T.A., Dittberner, A.B., \& Johnson, E.E. (2008). High-frequency amplification and sound quality in listeners with normal trough moderate hearing loss. Journal of Speech and Heaing Research 51(1): 160-172.

Robinson, J, D., Baer, T., \& Moore, B.C.J. (2007). Using transposition to improve consonant discrimination and detection for listeners with severe high-frequency hearing loss. International Journal of Audiology $l 46$ (6): 293-308.

Shipley, K.G., \& McAfee, J.G. (2004). Assessment in speech-language pathology. A resource manual. (3rd ed.) New York: Thomson/Delmar Learning

Simpson, A., Hersbach, A.A., \& McDermott, H.J. (2005). Improvements in speech perception with an experimental nonlinear frequency compression hearing device. International Journal of Audiology 44(5): 281-292.

Simpson, A., Hersbach, A.A., \& McDermott, H.J. (2006). Frequency-compression outcomes in listeners with steeply sloping audiograms. International Journal of Audiology 45(11): 619-629.

Spitzer, J.B., Mancuso, D., \& Cheng, M. (2008). Development of a clinical test of musical perception: Appreciation of music in cochlear implantees (AMICI). Journal of the American Academy of Audiology 19(1): 56-81.

Statistics South Africa (2001). South African Statistics Council on Census 2001. Retrieved from http://www.statssa. gov.za/timeseriesdata/pxweb2006/Dialog/Saveshow.asp.

Stuermann, B. (2009). Field Study News: Audéo Yes. SoundRecover for mild to moderate hearing loss. Retrieved on 21 July 2010 from www.phonak.com

Turner, C.W., \& Hurtig, R.R. (1999). Proportional frequency compression of speech for listeners with sensorineura hearing loss. Journal of the Acoustical Society of America 106(2): 877-886.

Van Deun, L., van Wieringen, A., van den Bogaert, T., Scherf, F., Offeciers, F.E., van de Heyning, P.H., Desloovere, C., Dhooge, I.J., Deggouj, N., De Raeve, L., \& Wouters, J. (2009). Sound localization, sound lateralization, and binaural masking level differences in young children with normal hearing. Ear and Hearing 30(2): 178-190.

Vestergaard, M.D. (2003). Dead regions in the cochlea: Implications for speech recognition and applicability of articulation index theory. International Journal of Audiology 42(5): 249-261.

Wessel, D., Fitz, K., Battenberg, E., Schmeder, A., \& Edwards, B. (2007). Optimizing hearing aids for music listening. Retrieved on 7 February 2009 from http://cnmat.berkeley.edu/publication/optimizing_hearing_aids_music listening.

Zielinski, S., Rumsey, F., \& Bech, S. (2008). On some biases encountered in modern audio quality listening tests - a review. Journal of the Audio Engineering Society 56(6): 427-451. 

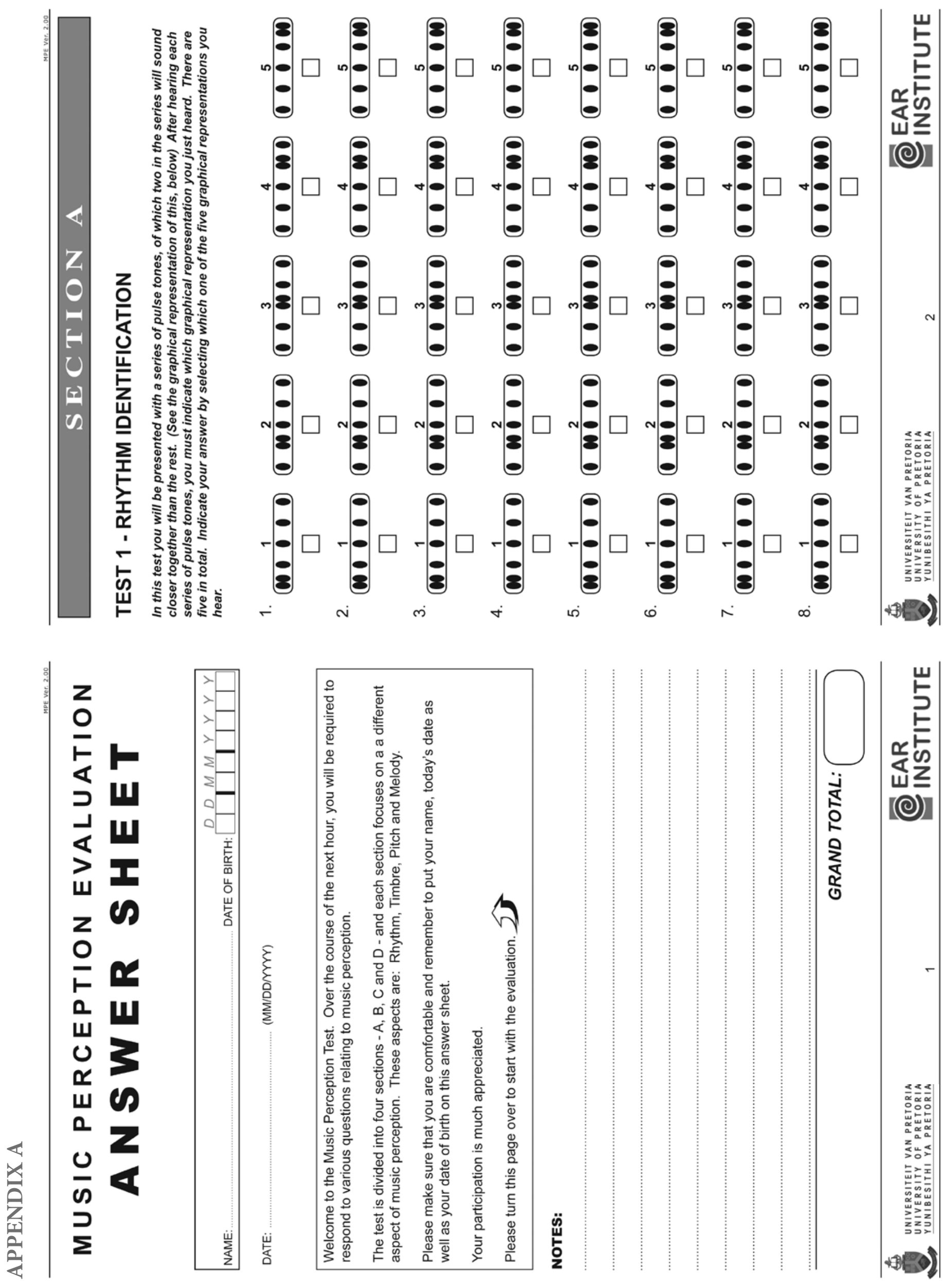


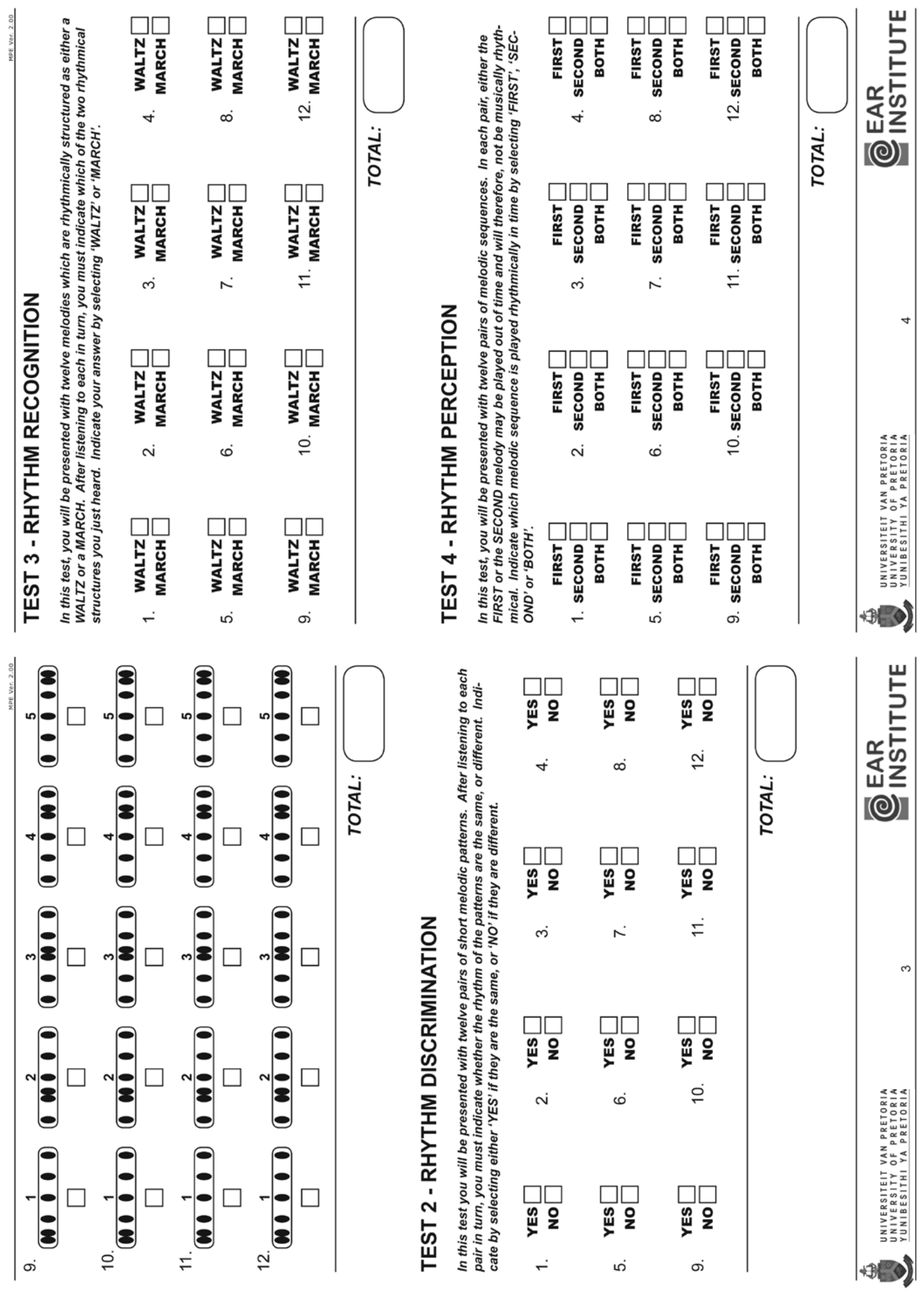



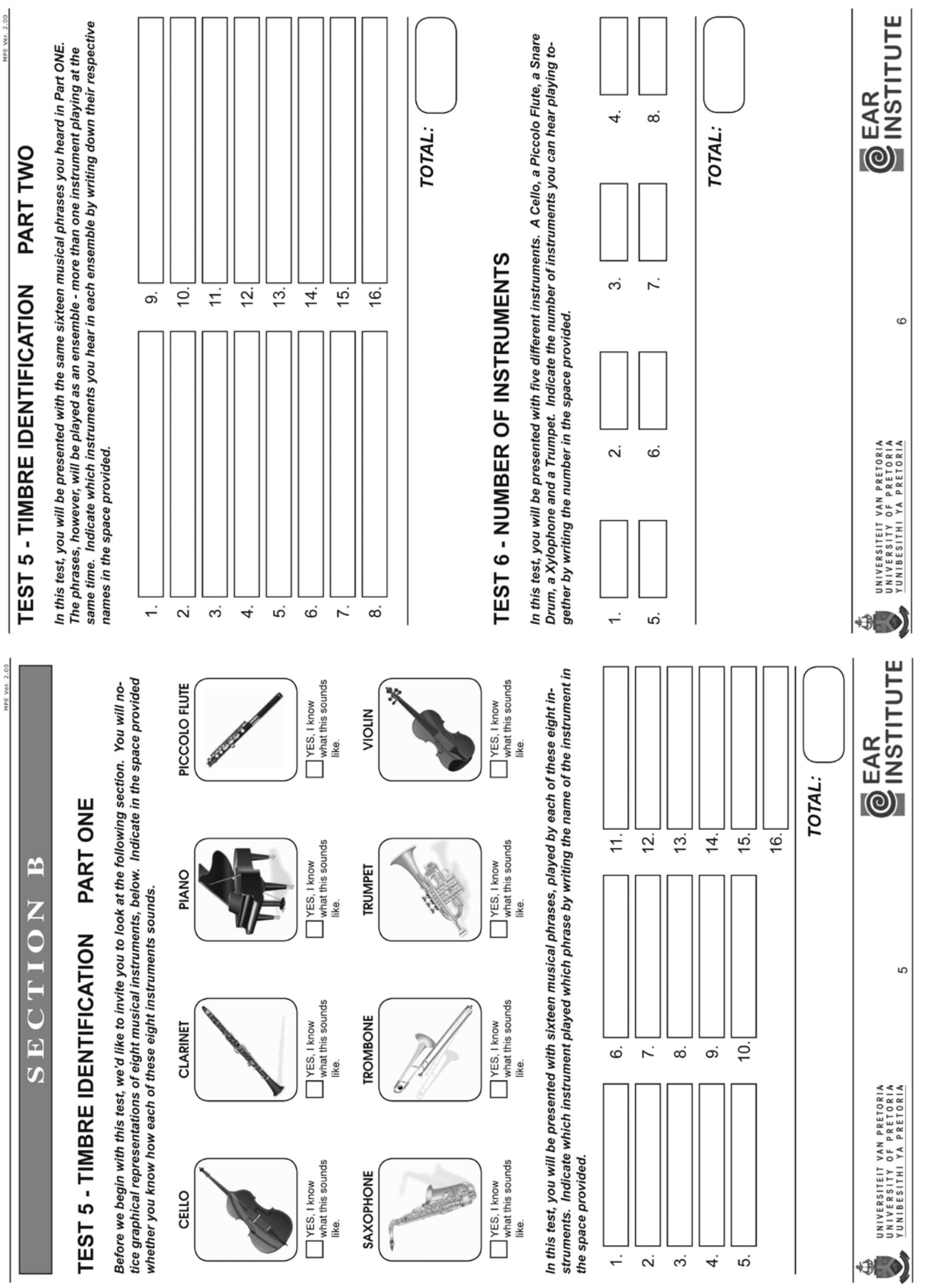


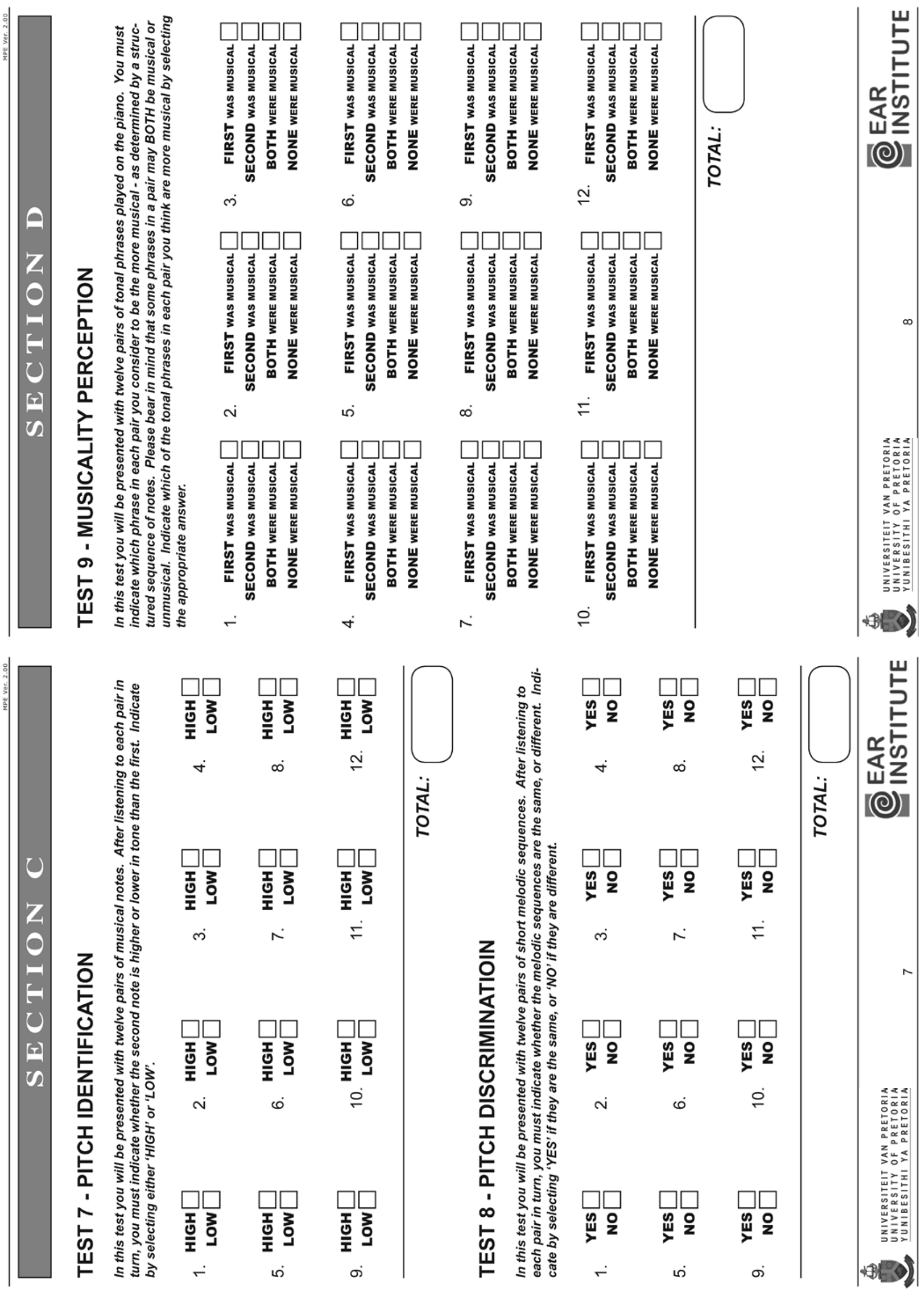




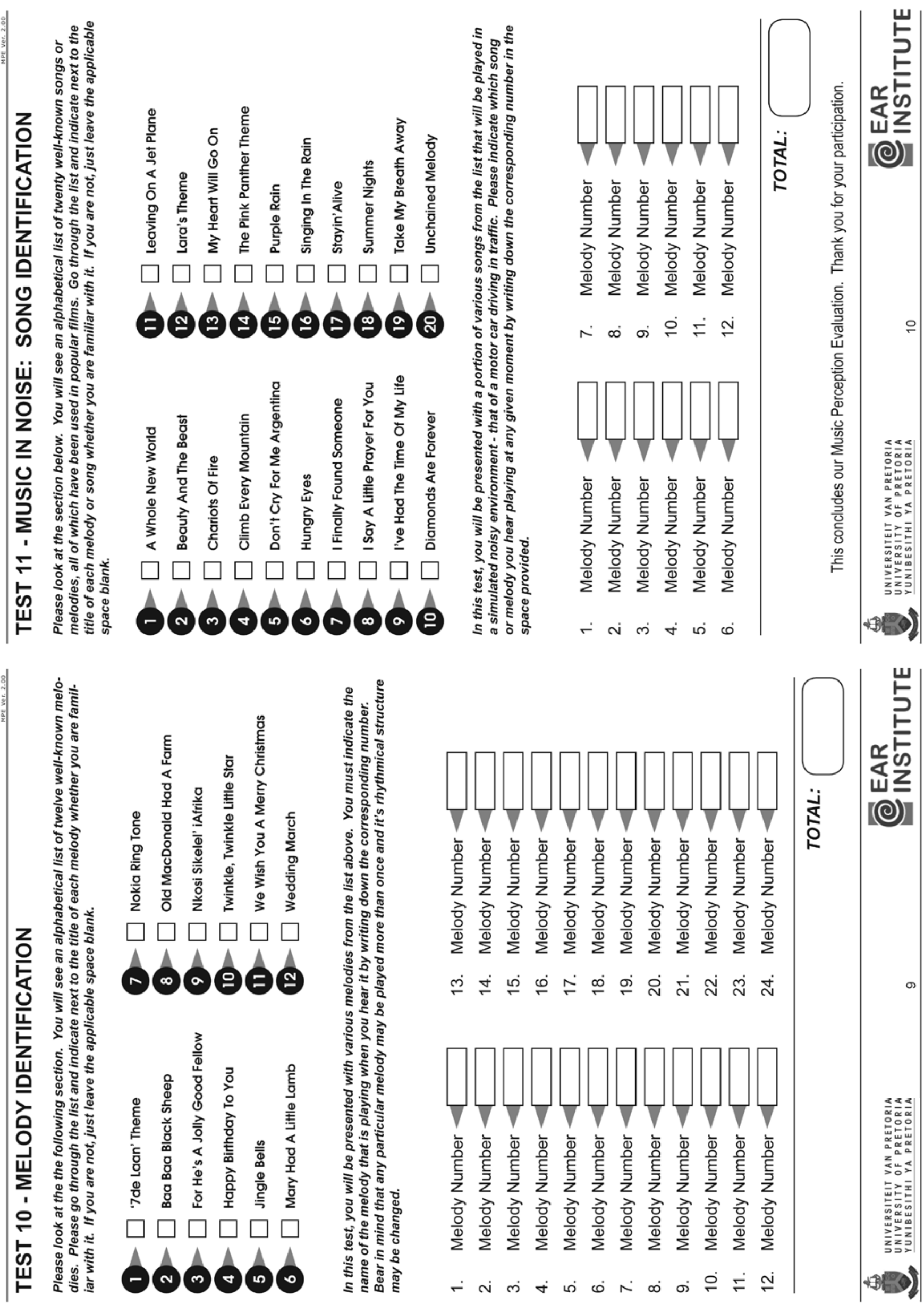




\section{APPENDIX B: MUSIC PERCEPTION TEST: USER GUIDE}

\section{Background to the test}

Aim. This test was compiled with the purpose of obtaining objective information regarding hearing-aid users' perception of music.

Rationale. The ability to enjoy music is often adversely affected by a hearing loss (Glista \& McDermott, 2008:2) and the majority of people wearing hearing instruments complain of the reduced sound quality of music heard through their personal amplification devices (Chasin \& Russo, 2004:35). This may be due to the fact that most hearing instruments are designed with the focus on hearing speech sounds and not music, which is often problematic as there are several differences between speech and music.

More and more people with hearing problems are expressing an equal need for their hearing instruments to be fitted optimally for listening to music (Chasin, 2004:10). The escalating interest in musical perception accuracy and enjoyment is also reflected in publications of a variety of investigations utilising different experiments to assess performance on musical tasks (Fujita \& Ito, 1999; Gfeller et al., 2005, 2002, 1997 \& 1991; Looi et al., 2008; Nimmons et al., 2008). Most of these studies were, however, done on cochlear implantees and not hearing-aid users. To complicate matters, there is no standard test of music perception, and different musical styles thrive in strikingly different acoustical environments (Wessel et al., 2007:1). A further limitation to the choice of measures to access currently available musical skills is that most music tests are designed to examine the skills of individuals undergoing formal musical training (Don et al., 1999:158). The aforementioned information highlights the need for a clinically relevant measure of musical recognition and performance by hearing-aid users in order to improve their quality of life as well as the services delivered to them.

Conclusion. Not only is the technology for music input still in its infancy, but the research and clinical knowledge of what music lovers need to hear are also still in early stages of understanding (Chasin \& Russo, 2004:35) and clearly, more research is required in this area. This test was designed to address the abovementioned and included different aspects of music perception including rhythm, timbre, pitch and melody.

\section{Requirements and set-up \\ Requirements}

The test is available on CD and therefore you need a CD player for presentation. The CD player has to be connected to a two-channel clinical audiometer as it is presented through the audiometer to the participant sitting inside the soundproof room. The soundproof room should therefore be equipped with speakers as the test is presented in free field inside the soundproof room.

A copy of the music perception test (MPT)'s answer sheet and a pen/ pencil should be provided to the participant as all answers are written directly on the answer sheet.

\section{Set-up}

Ensure beforehand that the CD player and speakers are in good working order to avoid any difficulties during the test procedures and to avoid distortion. Connect the $\mathrm{CD}$ player to the audiometer with the cords provided from the $\mathrm{CD}$ player manufacturers in the following manner:

- The cord from the CD player with only one fitting should be inserted into the audiometer at the opening marked '1761-9621 (5VDC.2A)'.

- The other cord from the CD player consists of two fittings (red and white). The red fittings should be inserted into the audiometer at the opening marked ' $\mathrm{A}$ ' and the white fitting just next to it, at the opening marked 'B'.

The participant should be seated inside the soundproof room, facing the speaker at 45 degrees, at a distance of approximately 1 metre.

\section{Running the test}

To present the MPT through the audiometer, the following settings should be selected on the audiometer:

\section{Channel 1}

Speaker

External A

Right

Interrupt on

$75 \mathrm{~dB}$

Channel 2
Speaker
External B
Left
Interrupt on
$75 \mathrm{~dB}$

After selecting these settings, the test examiner should press 'play' on the CD player to start the test. No further selections on the CD player are necessary as the different sub-tests continuously follow one another.

It is suggested that a level of $75 \mathrm{~dB}$ is selected for the presentation of the test and that hearing-aid users are permitted to adjust the volume on their hearing aids for maximum comfort.

The participant will have an answer sheet with a set of written instructions for each test section. All instructions are also presented by the speakers before the onset of each test. A written response from the participant is required for each stimulus in the test. Every test includes two practice items which precede the actual test items.

\section{The specific sub-tests}

\section{Section A: Rhythm}

\section{Test 1. Rhythm identification}

In this, test the participant is presented with a series of pulse tones, of which 2 in the series will sound closer together than the rest. After hearing each series of pulse tones, the participant must indicate which graphical representation he/she just heard. There are 5 in total. The participant indicates his/her answer by selecting which 1 of the 5 visual representations on the answer sheet corresponded to the rhythmic pattern they heard. A total of 10 items is included in this sub-test.

The figure below (enlarged under 'Method') is for visual presentation of the short inter-pulse interval at position 4 as used in item 5 .

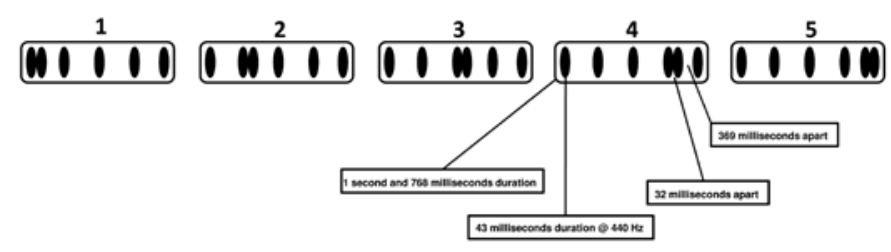

\section{Test 2. Rhythm discrimination}

In this test, the participant will be presented with 10 pairs of short melodic patterns. After listening to each pair in turn, the participant must indicate whether the rhythm of the patterns is the same, or different. The participant indicates his/her answer by selecting either 'YES' if they are the same, or 'NO' if they are different.

The example below is to indicate that the pairs of rhythms are the same, as presented in item 1.

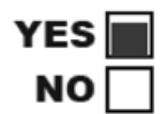

\section{Test 3. Rhythm recognition}

In this test, the participant will be presented with 10 melodies which are rhythmically structured as either a WALTZ or a MARCH. After listening to each in turn, the participant must indicate which of the 2 rhythmical structures he/she has just heard. The answer is indicated by selecting either 'WALTZ' or 'MARCH'.

The example below is to indicate that the rhythmical structure was that of a march, as presented in item 5 . 


\section{WALTZ MARCH}

\section{Test 4. Sensing rhythm}

In this test, the participant will be presented with 10 pairs of melodic sequences. In each pair, either the FIRST or the SECOND melody may be played out of time and will therefore not be musically rhythmical. The participant should indicate which melodic sequence is played rhythmically in time by selecting 'FIRST', 'SECOND' or 'BOTH'.

The example below is to indicate that BOTH melodic sequences were played in time, as presented in item 7 .

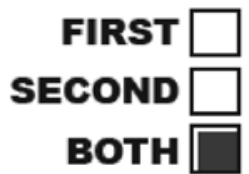

\section{Section B: Timbre}

Test 5. Timbre identification (single instruments)

Participants are asked to indicate which of the musical instruments represented by graphical representations are familiar to them before the onset of the test. They are then presented with sixteen musical phrases, played by each of the eight instruments demonstrated and are asked to indicate which instrument played which phrase by writing the name of the instrument in the space provided.

The example below is to indicate that the participant was familiar with a cello and wrote its name on the answer sheet as presented in item 10 .

\section{CELLO}

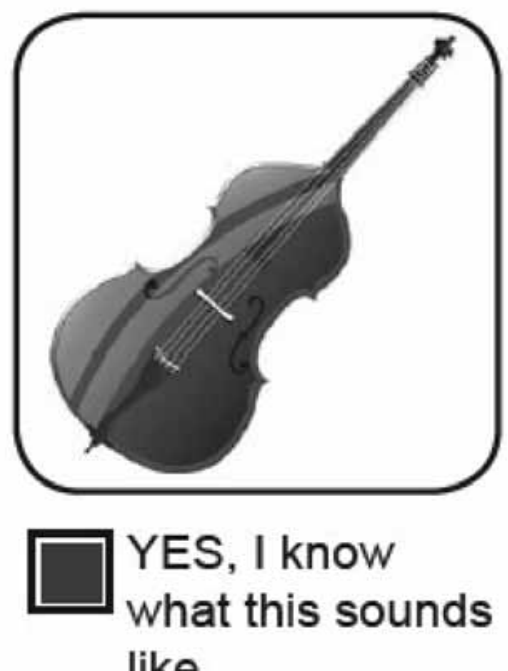

like.

\section{CELLO}

Test 5. Timbre identification (multiple instruments)

In this test, participants are presented with the same 16 musical phrases heard in the previous test. The phrases, however, will be played as an ensemble - more than one instrument playing at the same time. The participant is required to indicate which instruments he/she hears in each collection by writing down their respective names in the space provided.
The example below is to indicate that the following three instruments played together during item 7 .

\section{CELLO/PIANO/TROMBONE}

\section{Test 6. Identification of the number of instruments}

In this test, participants are presented with 5 different instruments: a cello, piccolo flute, snare drum, xylophone and trumpet. They are required to indicate the number of instruments they can hear playing together by writing down the number in the space provided.

The example below is to indicate that four instruments played together as presented in item 1 .

\section{4}

\section{Section C: Pitch}

\section{Test 7. Pitch identification}

In this test, participants will be presented with 10 pairs of musical notes. After listening to each pair in turn, they must indicate whether the second note is higher or lower in tone than the first. The answer is indicated by selecting either 'HIGH' or 'LOW'.

The example below is to indicate that the second note was higher in tone than the first, as presented in item 9 .

\section{HIGH$$
\text { Low }
$$

\section{Test 8. Pitch discrimination}

In this test, participants will be presented with 10 pairs of short melodic sequences. After listening to each pair in turn, they must indicate whether the melodic sequences are the same, or different. The answer is indicated by selecting 'YES' if they are the same, or 'NO' if they are different.

The example below is to indicate that the pair of melodic sequences was different, as presented in item 6 .

\section{\begin{tabular}{r|r} 
YES \\
NO
\end{tabular}}

\section{Section D: Melody}

\section{Test 9. Musicality}

In this test, participants are presented with 10 pairs of tonal phrases played on the piano. They must indicate which phrase in each pair they consider to be the more musical or pleasant to listen to - as determined by a structured sequence of notes. Some phrases in a pair may BOTH be musical or unmusical.

The example below is to indicate that the first musical phrase was musical, as presented in item 1 .

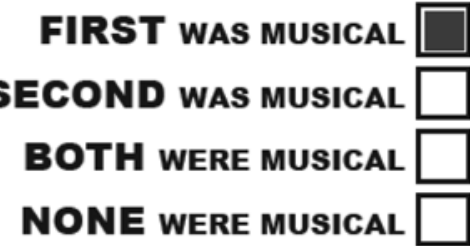




\section{Test 10. Melody identification}

Participants are presented with an alphabetical list of 10 well-known melodies and are asked to indicate next to the title of each melody whether they are familiar with it. If they are not familiar with it, they are instructed to leave the applicable space blank. They are then presented with various melodies from the abovementioned list and asked to indicate the name of the melody that is playing when they hear it by writing down the corresponding number. Any particular melody can be played more than once, and its rhythmical structure may be changed. If participants need more time to consider their choice, they should indicate this to the examiner by raising a hand.

The example below is to indicate that the participant was familiar with the melody 'Jingle Bells' and wrote the corresponding number on the answer sheet as presented in item 8.

\section{Jingle Bells}

\section{Melody Number 3}

\section{Test 11. Music in noise: song identification}

Participants will see an alphabetical list of 20 well-known songs of which all have been used in popular films. They are required to go through the list and indicate next to the title of each song or film whether they are familiar with it. If they are not familiar with it, they are instructed to leave the applicable space blank. Participants are then presented with a portion of various songs from the list that will be played in a simulated noisy environment - that of a motor car driving in traffic. They should indicate which song they hear playing or the movie it's from, by writing down the corresponding number in the space provided.

The example below is to indicate that the participant was familiar with the song, 'Leaving on a Jet Plane', and wrote the corresponding number on the answer sheet as presented in item 9.

\section{$11-\square$ Leaving On A Jet Plane from "Armageddon" \\ Melody Number 11}

\section{CD tracks}

The test consists of 14 tracks and takes 57.17 minutes to complete.

Track 1 Introduction

Track 2 Test 1 . Rhythm identification

Track 3 Test 2. Rhythm discrimination

Track 4 Test 3. Rhythm recognition

Track 5 Test 4 . Sensing rhythm

2.42

4.09

4.24

Track 6 Test 5. Timbre identification (single instruments) 5.19

Track 7 Test 5. Timbre identification (multiple instruments) 5.39

Track 8 Test 6. Identification of number of instruments $\quad 5.10$

Track 9 Test 7. Pitch identification $\quad 2.39$

Track 10 Test 8. Pitch discrimination $\quad 4.00$

Track 11 Test 9 . Musicality $\quad 4.51$

Track 12 Test 10. Melody identification 5.58

Track 13 Test 11. Music in noise: song identification $\quad 7.26$

Track 14 End

\section{APPENDIX C. MUSIC PERCEPTION TEST EVALUATION SHEET}

Please read the following questions carefully and answer them by encircling the applicable answer. Should you wish to add any comments, space has been provided at the end of the evaluation sheet. Please do not leave any question unanswered.

Do you feel that the test appears to measure music perception based on its appearance (in other words, does it look like a music perception test)?

$\begin{array}{lllllll}\text { Yes } & 5 & 4 & 3 & 2 & 1 & \text { No }\end{array}$

In your opinion, does the test represent a complete assessment of music perception and include the assessment of a whole spectrum of musical skills?

$\begin{array}{lllllll}\text { Yes } & 5 & 4 & 3 & 2 & 1 & \text { No }\end{array}$

Are you satisfied that the stimuli included in the test are suitable for the assessment of music perception in hearing-aid users?

$\begin{array}{lllllll}\text { Yes } & 5 & 4 & 3 & 2 & 1 & \text { No }\end{array}$

In your opinion, do the included stimuli have various levels of difficulty and are therefore not too easy or too difficult?

$\begin{array}{lllllll}\text { Yes } & 5 & 4 & 3 & 2 & 1 & \text { No }\end{array}$

Do you feel that the instructions are clear and precise and therefore enable examinees to understand what is expected of them?

$\begin{array}{lllllll}\text { Yes } & 5 & 4 & 3 & 2 & 1 & \text { No }\end{array}$

Are you satisfied that the language used in the test is unbiased?

$\begin{array}{lllllll}\text { Yes } & 5 & 4 & 3 & 2 & 1 & \text { No }\end{array}$

In your opinion, is the test logically organised?

$\begin{array}{lllllll}\text { Yes } & 5 & 4 & 3 & 2 & 1 & \text { No }\end{array}$

Do you feel that sufficient time is provided to answer questions?

$\begin{array}{lllllll}\text { Yes } & 5 & 4 & 3 & 2 & 1 & \text { No }\end{array}$

Are you satisfied that the test recording is of a high quality?

$\begin{array}{lllllll}\text { Yes } & 5 & 4 & 3 & 2 & 1 & \text { No }\end{array}$

Do you feel that the test and test items are appropriate for the South African context and do not consist of culturally biased items, phrases or situations that might be offensive to some individuals?

$\begin{array}{lllllll}\text { Yes } & 5 & 4 & 3 & 2 & 1 & \text { No }\end{array}$

Please state any additional comments you may have regarding the test. 

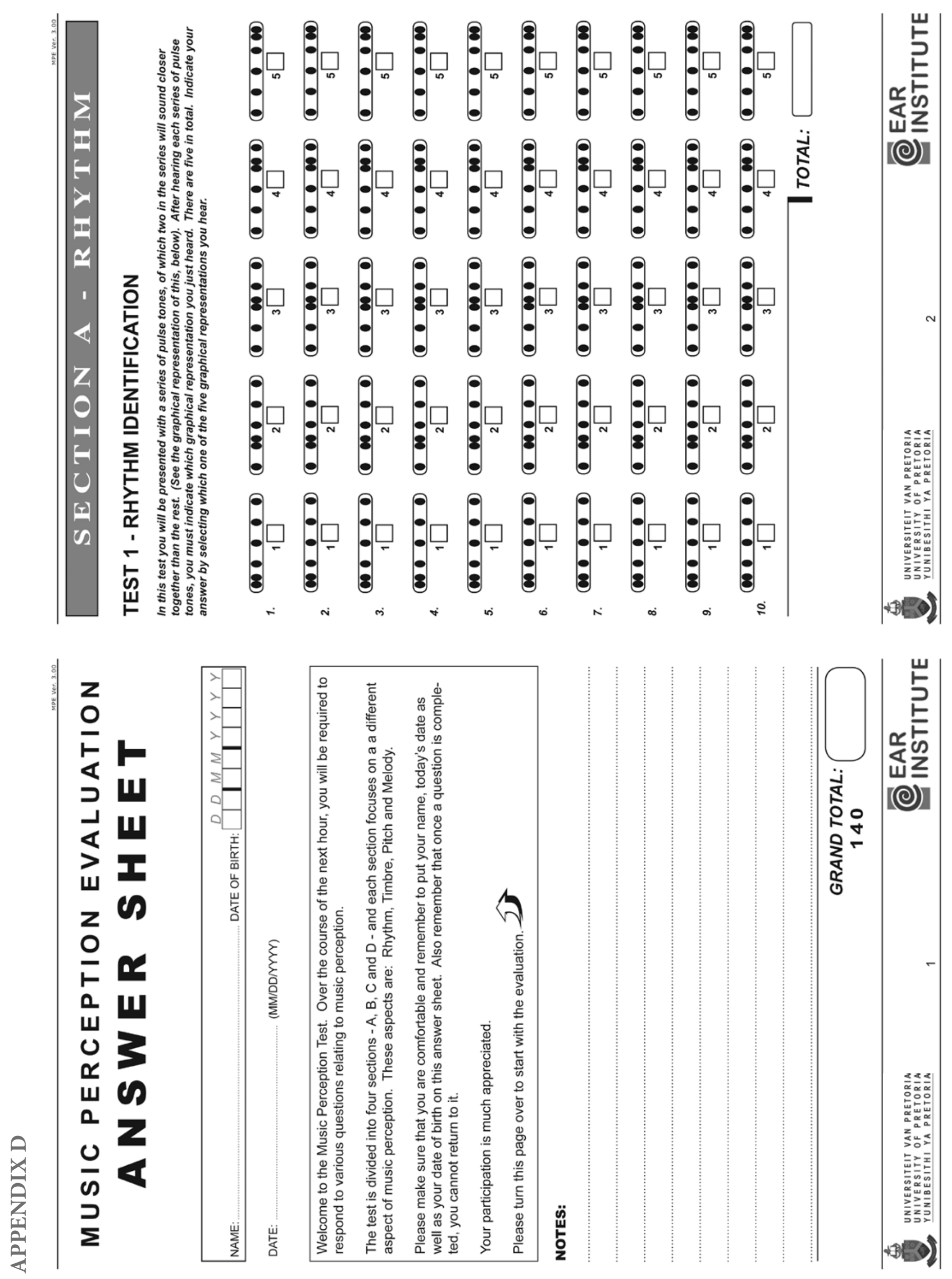


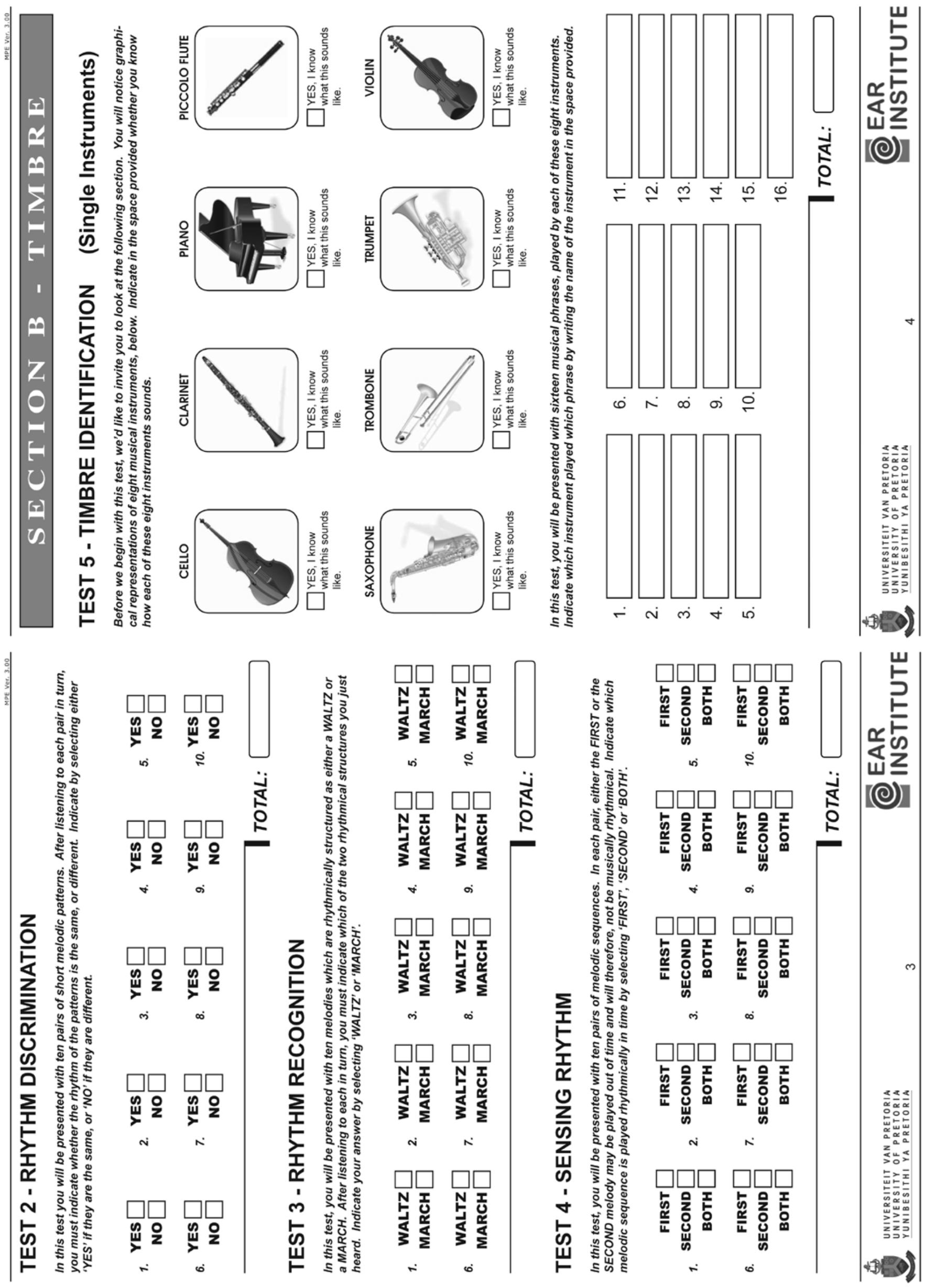




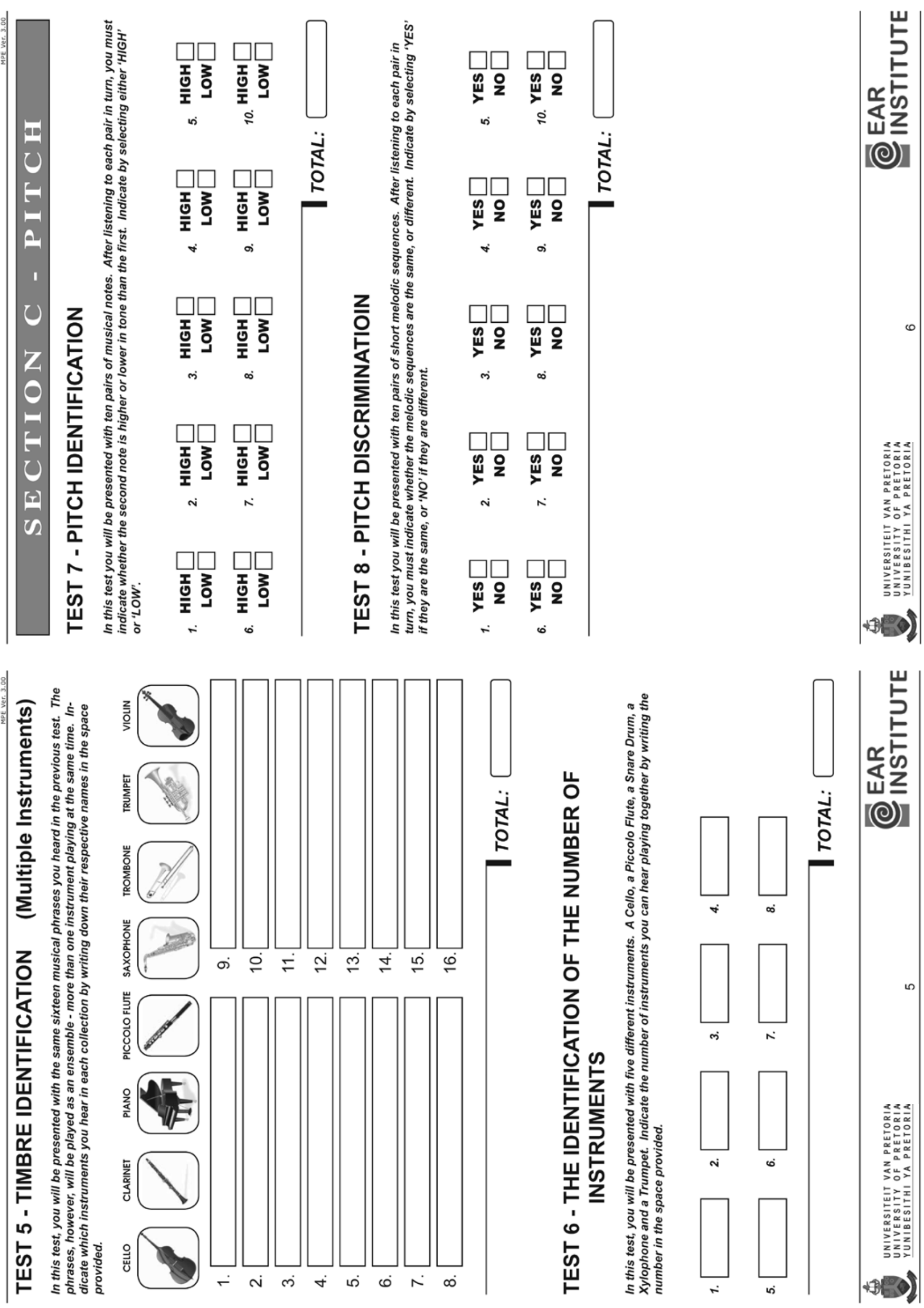




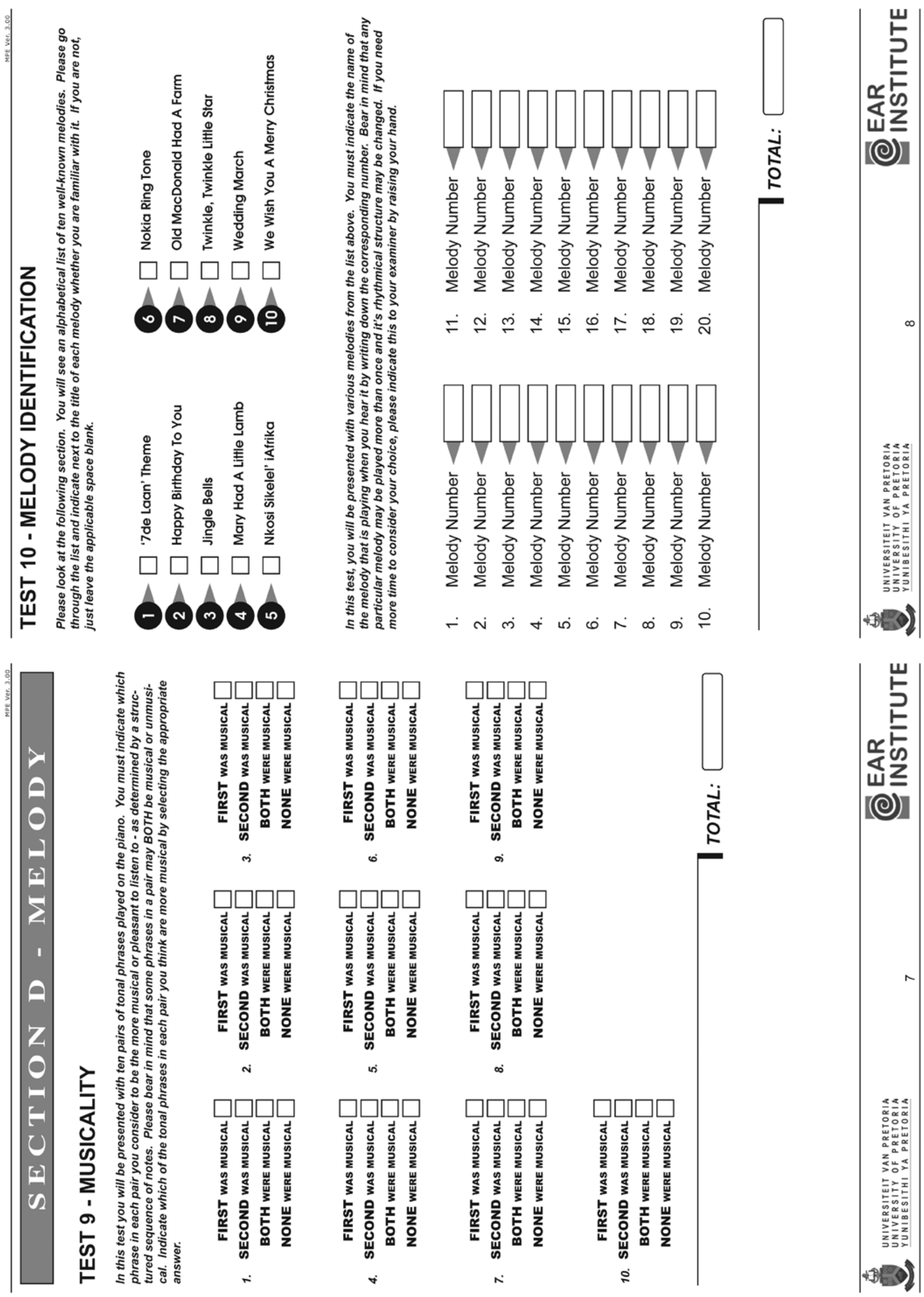




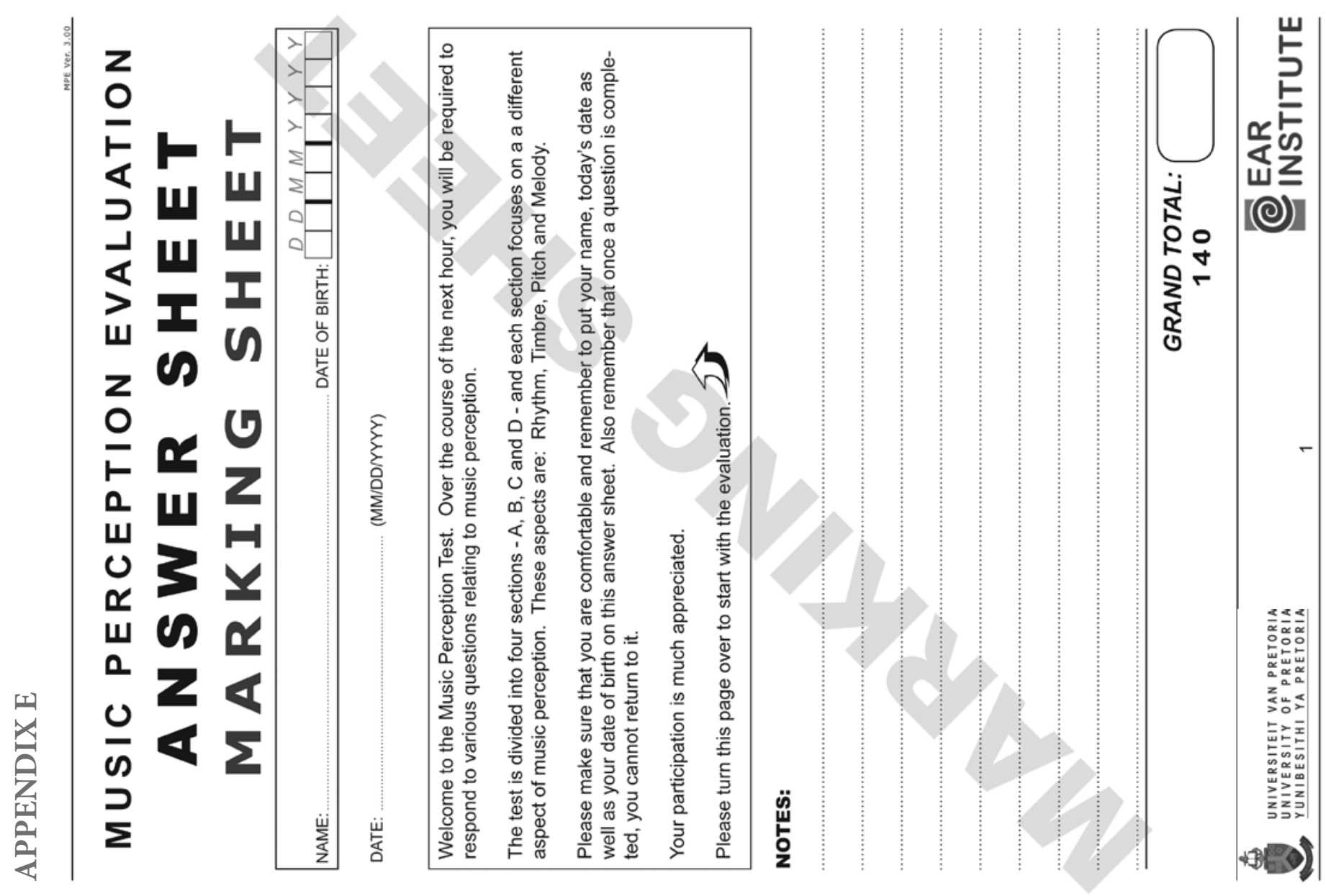

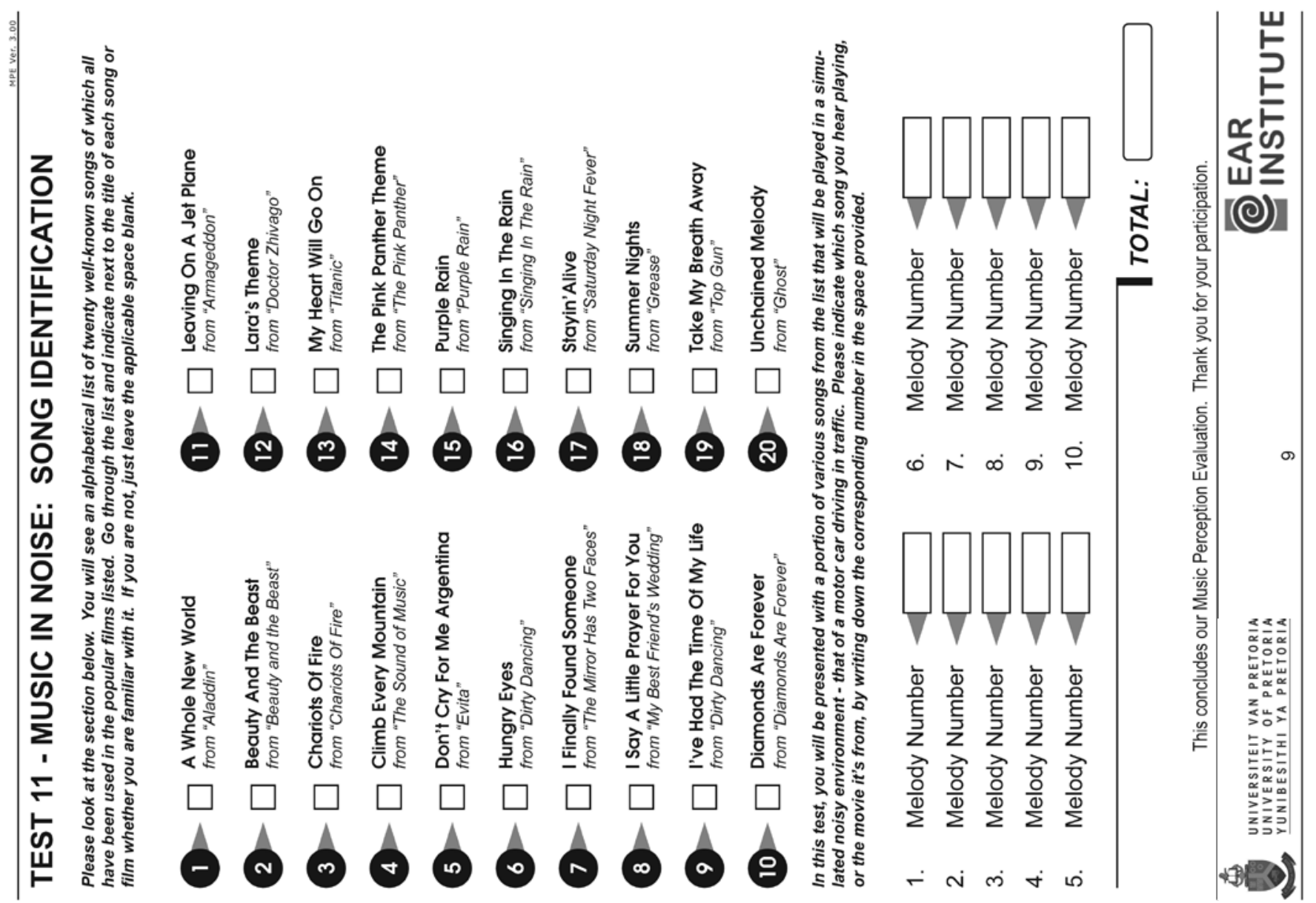



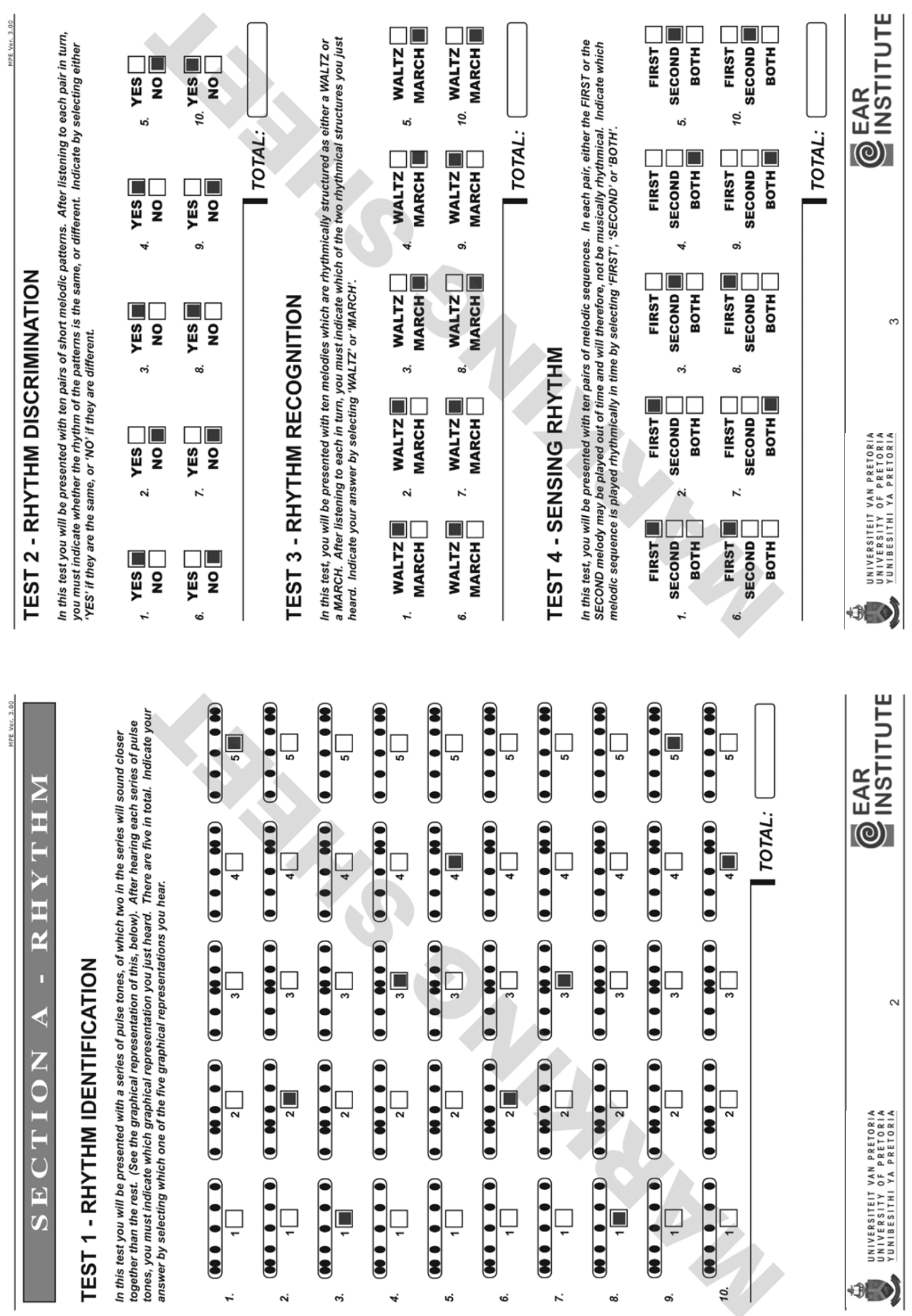

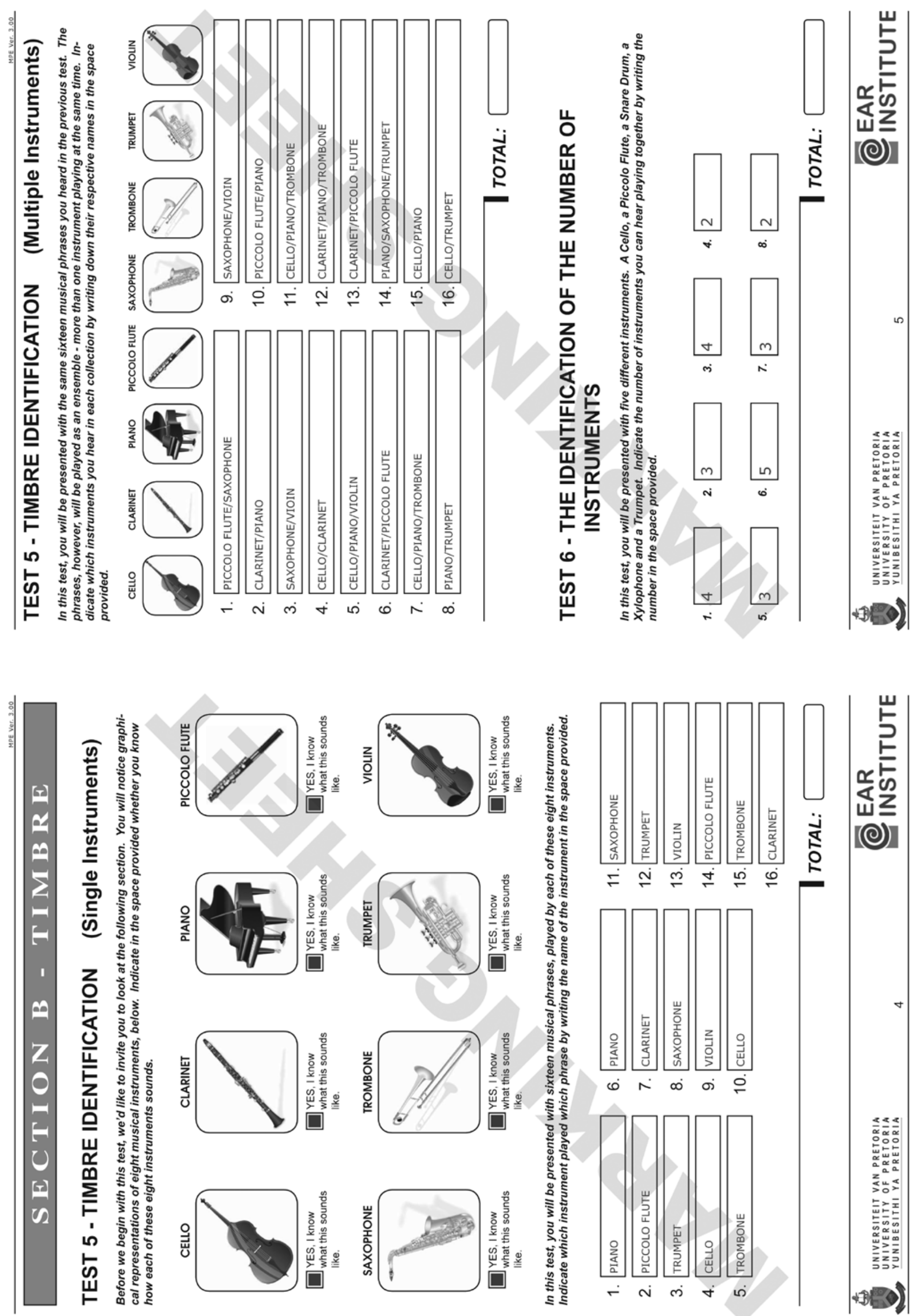

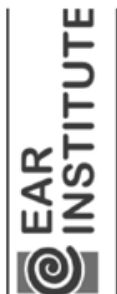

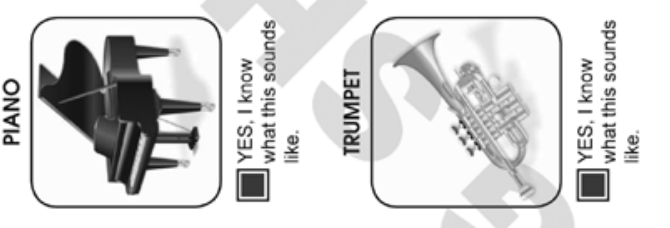

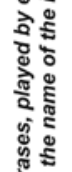

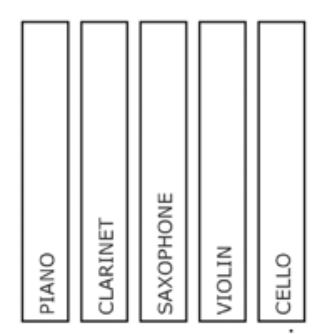

ம $r \dot{\infty} \dot{\circ}$
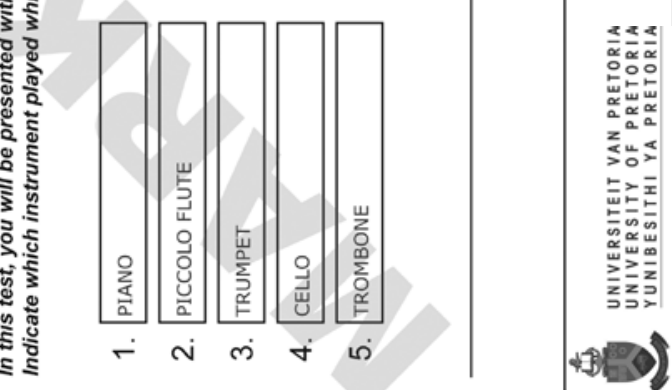

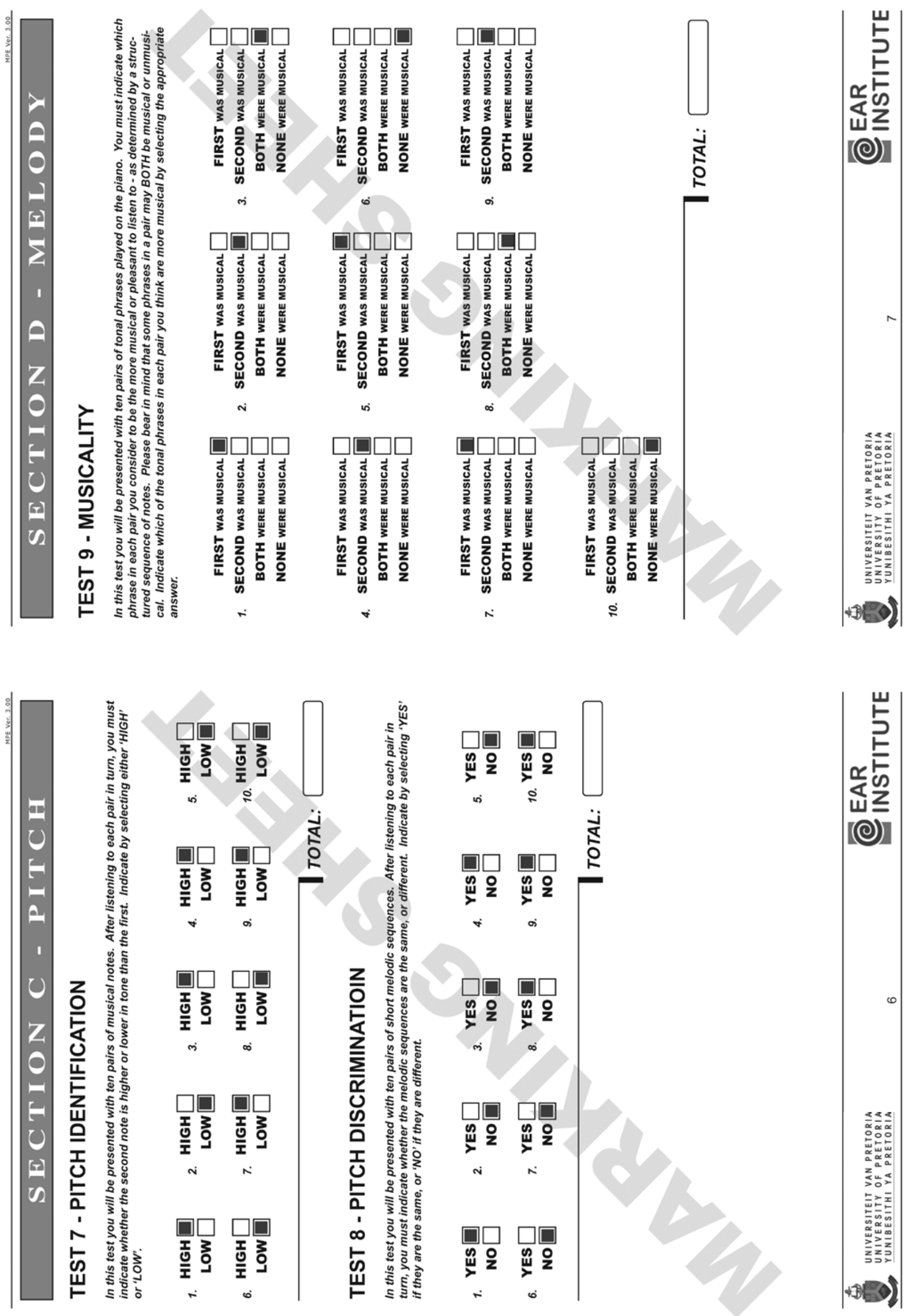

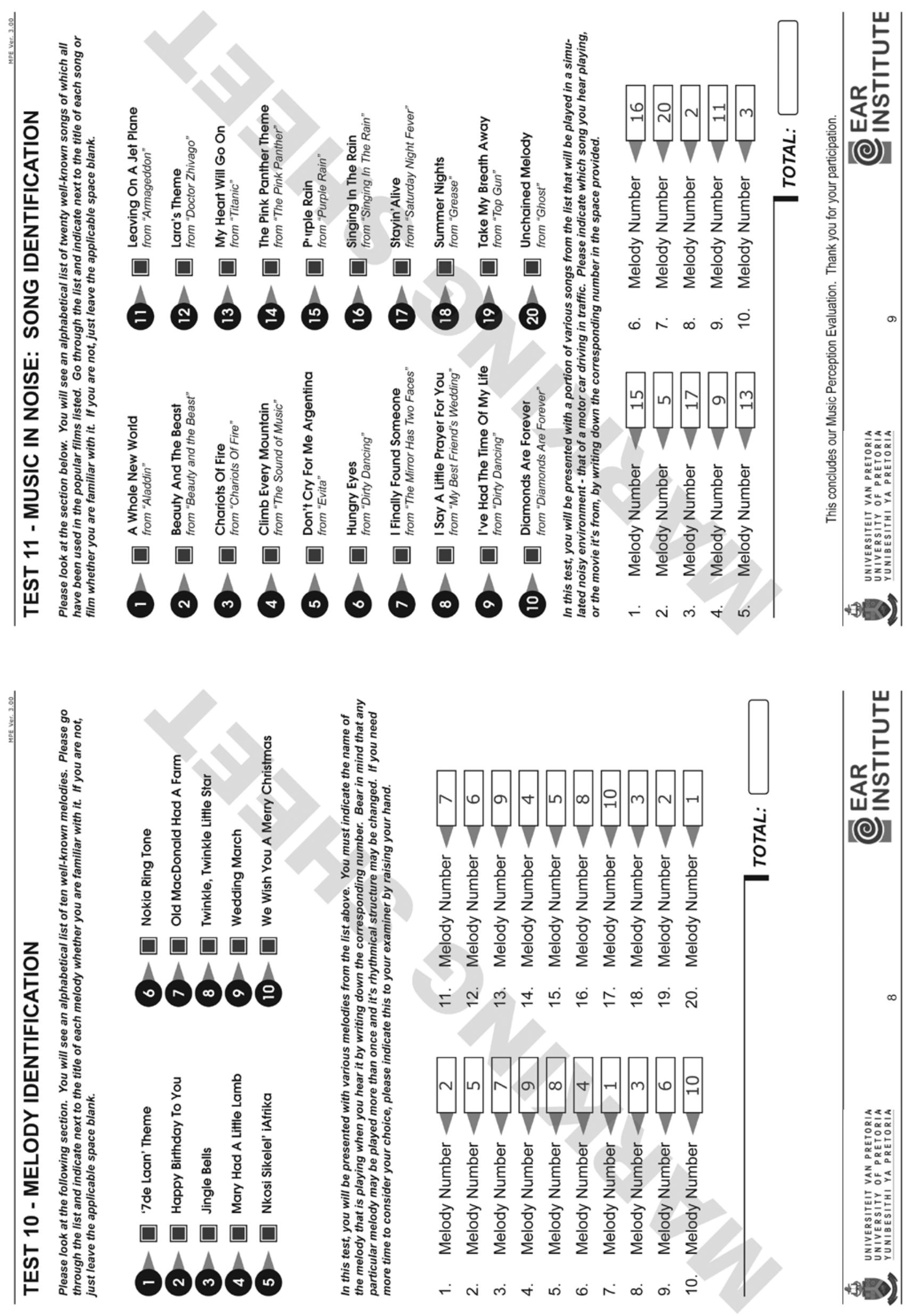